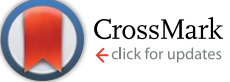

Cite this: J. Mater. Chem. A, 2016, 4, 17913

Received 7th August 2016

Accepted 16th October 2016

DOI: $10.1039 / c 6 t a 06757 c$

www.rsc.org/MaterialsA

\section{Trends in electrode development for next generation solid oxide fuel cells}

\begin{abstract}
Wang Hay Kan, $\dagger^{\mathrm{ab}}$ Alfred Junio Samson $\dagger^{\mathrm{b}}$ and Venkataraman Thangadurai ${ }^{\star \mathrm{b}}$
High temperature electrochemical devices, such as solid oxide fuel cells (SOFCs), will play a vital role in the future green and sustainable energy industries due to direct utilization of carbon-based fuels and their ability to couple with renewable energies to convert by-products into valuable fuels using solid oxide electrolysis cells (SOECs). All-solid-state design provides a great opportunity toward the optimization of durability, cost, efficiency and robustness. Electrodes, one of the most important components that facilitate the electrochemical redox reactions, have been actively investigated for several decades to optimize a matrix of chemical composition, microstructure, and performance. Although some mixed ionic electronic conductors (MIECs) can provide electrochemically active surface with excellent chemical tolerance comparing to the composite electrodes made of conventional ceramic electrolyte and metal (cermet), their electrochemical activities may not be high enough to obtain a desirable power, even at moderate temperature operation. This shortage could be improved by engineering the microstructure of the electrodes, which control electrochemically active sites in SOFCs and SOECs. In this article, the current trends in electrode-engineering techniques for advanced SOFCs are reviewed.
\end{abstract}

${ }^{a}$ China Spallation Neutron Source, Institute of High Energy Physics, Chinese Academy of Sciences, Dongguan Institute of Neutron Science, Dongguan, China 523803

${ }^{b}$ University of Calgary, 2500 University Dr. NW, Calgary, Alberta, Canada T2N $1 \mathrm{~N} 4$. E-mail:vthangad@ucalgary.ca

$\dagger$ These authors contributed equally.

\section{Introduction}

The ever-growing concern over the availability of fossil fuel resources and the unpredictably adverse climatic conditions have driven many countries to attempt to decrease greenhouse gas

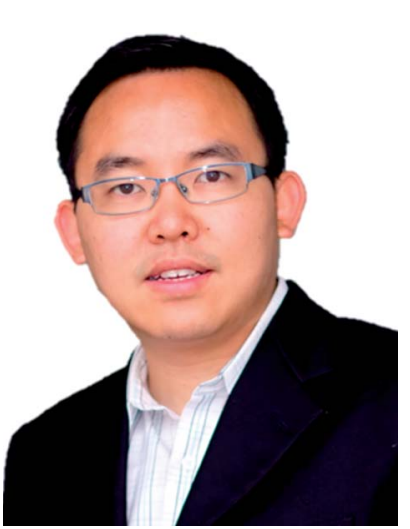

Dr Wang Hay Kan obtained his BSc (Chemistry) from the Hong Kong University of Science and Technology in 2006 where he worked in Prof. Ian D. Williams' lab on coordination polymers. After that, he continued his MSc (Chemistry) study with Prof. Linda F. Nazar at the University of Waterloo on lithium-ion battery cathodes, particularly on the morphology control of olivine-type $\mathrm{LiMPO}_{4}(\mathrm{M}=\mathrm{Mn}$, $\mathrm{Fe}$, and Co). He joined Prof. Venkataraman Thangadurai's group in the University of Calgary for his PhD in Chemistry, and researched unconventional mixed conductive anodes for SOFCs. SAubsequently, he worked as a postdoctoral fellow in the Manthiram group at the University of Texas at Austin and continued his battery and fuel cell research studies from 2014 to 2015. Recently, Dr Kan joined as a beamline scientist/associate researcher at the China Spallation Neuron Source at the China Academy of Sciences.

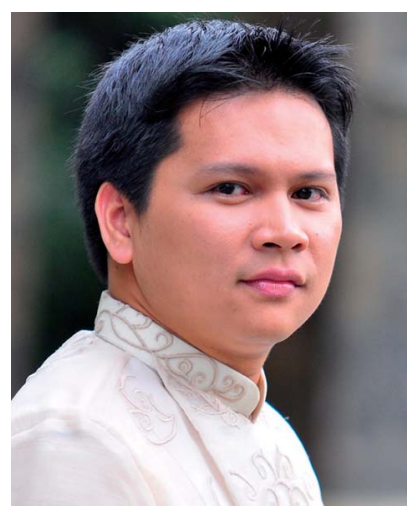

Dr Alfred Junio Samson obtained his BSc (Physics) from the University of the Philippines Diliman in 2004 and his double MSc (Materials Science and Engineering) from Luleå University of Technology in Sweden and Saarland University in Germany in 2008. He received his $\mathrm{PhD}$ in Energy Conversion in 2012 from the Technical University of Denmark (DTU), Roskilde, Denmark. He continued as a postdoctoral research fellow in DTU, where his research was focused on developing nanoscale electrocatalysts for SOFCs and ceramic oxygen separation membranes. In 2015, he joined the group of Prof. Venkataraman Thangadurai and continued his postdoctoral research fellow work at the University of Calgary. His current research is geared towards the development of all-solid-state energy technologies such as batteries and SOFCs using cost effective and simple assembly techniques. 
emissions and shift towards renewable energy resources. Recently in Canada, there is great interest in integrating coalfired power plants with $\mathrm{CO}_{2}$ capture technology to deliver pure $\mathrm{CO}_{2}$ to the oil fields for enhanced petroleum extraction. ${ }^{1}$ On the other hand, the successful implementation of renewable energies would require mature energy storage and conversion systems, since those resources and their usages are often intermittent. ${ }^{2}$ Among the various systems proposed, fuel cells are amongst the most promising energy conversion systems due to their high theoretical efficiency $\left(83 \%\right.$ at $\left.25{ }^{\circ} \mathrm{C}\right)$ to yield electricity and heat..$^{3-5}$ For large and domestic applications, solid oxide fuel cells (SOFCs) provide unique advantages as cell components are made of non-precious ceramics, utilize hydrocarbon-type fuels, which are abundant, easy to transport and low-cost, and offer highenergy density. ${ }^{6,7}$ Fuel cells could be used in a wide range of applications, from small scale power sources for portable and mobile electronic devices, small auxiliary power units for automotive applications and combined heat and power systems for homes, to large central power generating systems. ${ }^{8}$ Also, highly selective electrochemical reactions yield negligible $\mathrm{NO}_{x} / \mathrm{SO}_{x}$ particulate emission making them environmentally cleaner technology. ${ }^{6}$ However, commercial SOFCs are expensive and rely heavily on government-subsidy. Only a handful of high-profile clients, such as Google and Walmart, have recently adopted SOFC technology. ${ }^{9}$

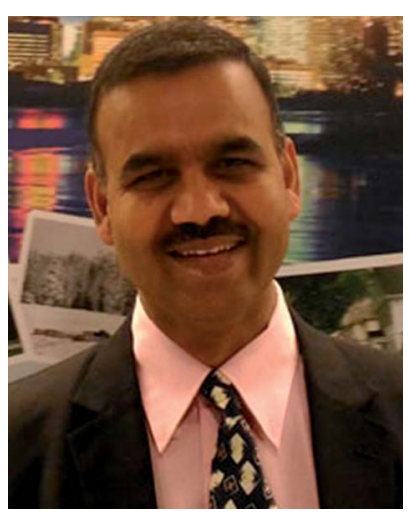

Dr Venkataraman Thangadurai is full professor of chemistry at the University of Calgary. He is a Fellow of the Royal Society of Chemistry, UK. He received his BSc from Sacred Heart College in Tirupattur, India in 1989 and his MSc from Muthurangam Government Arts College in Vellore, India in 1991. He received his PhD from the Indian Institute of Science, Bangalore, India in 1999 and did his PDF at the University of Kiel, Germany. He received a prestigious PDF fellowship from the Alexander von Humboldt Foundation, Bonn, Germany. In 2004, he received his Habilitation degree from the University of Kiel before starting his independent career in Calgary in 2005. His work at Kiel resulted in the development of a wide range of ceramic electrolytes, with a high voltage stability of $6 \mathrm{~V} / \mathrm{Li}$, that are able to conduct lithium ions for advanced robust and safe all-solid state Li batteries. His work in Calgary has resulted in the discovery of a wide range of novel ceramic, proton-conducting and oxide ion conducting electrodes and electrolytes for all-solid-state $\mathrm{Li}$ batteries, SOFCs, SOECs, and gas sensors, making materials that display high conductivities at low temperatures and function well in impure fuels. In 2016, he received the prestigious Keith Laidler Award from the Canadian Society of Chemistry for his outstanding contributions to physical chemistry. His current research activities include developing novel solid electrolytes and electrodes for advanced SOFCs, SOECs, all-solid-state batteries, and gas sensors.
The state-of-the-art SOFC is composed of perovskite-type $\mathrm{La}_{1-x} \mathrm{Sr}_{x} \mathrm{MnO}_{3}$ (LSM), Y-doped $\mathrm{ZrO}_{2}$ (YSZ), and Ni/YSZ (Ni/YSZ) as the cathode, electrolyte and anode, respectively, and typically operates between 800 and $1000{ }^{\circ} \mathrm{C}$. Such high temperature conditions are to facilitate the electrode reactions and to promote fast ionic movement in the electrolytes. Fig. 1 shows the schematic representation of a conventional YSZ-based SOFC. By lowering the operating temperature, the cost for operation and materials can be reduced, while the cell degradation problems, such as inter-diffusion between cell components, can also be mitigated. Moreover, cheap metal supports and steel interconnects could further cut the materials' cost significantly. However, lowering the operating temperatures also has some accompanying disadvantages: (i) slow electrode kinetics and decrease in oxide ion conductivity that lead to high polarization resistances; (ii) high ohmic polarization arises from resistances to electronic and ionic transport through the various cell components; (iii) high activation polarization is associated with resistance on electrode reaction kinetics and is dominant at low current densities and at low temperatures; and (iv) high concentration polarization dominates at high current densities, as the transport of reactive species to the electrolyte/ electrode interface becomes a limiting factor for the cell reaction at low temperatures.

To date, the performance of most of the reported SOFCs seems to be limited by the electrodes, thus requiring the search and development of improved anodes and cathodes for low-tomedium temperature SOFCs. The conventional electrode materials are yet to be optimized to perform at the intermediate temperatures $\left(500-700{ }^{\circ} \mathrm{C}\right)$, and alternative new electrodes with higher activity, chemical stability and durability should be developed. The aim of this article is to highlight the currently emerging electrode engineering approaches employed in the cathodes and anodes of SOFCs and its related technologies. Specifically, insights into the infiltration method in cathodes and the ex-solution method in anodes for SOFCs/SOECs are presented. The infiltration method is not only limited to application in cathodes, and the research activities concerning

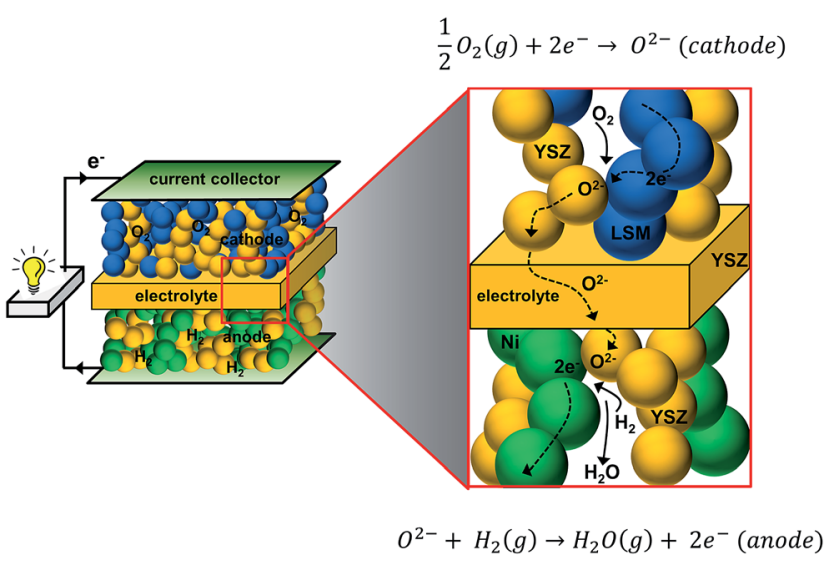

Fig. 1 Schematic diagram showing the operating principle of a solid oxide fuel cell (SOFC) (cathode: LSM + YSZ, electrolyte: YSZ, and anode: $\mathrm{Ni}+\mathrm{YSZ}$ ) 
the use of infiltration in anodes are about the same pace as in cathodes. ${ }^{\mathbf{1 0 - 1 2}} \mathrm{A}$ part of the review focuses and outlines specific trends and ideas within the topic of infiltration that have been sparking interest in recent years with SOFC cathodes. This article also aims to give an overview of the materials used in state-of-the-art electrodes for SOFCs together with motivation for employing electrode-engineering techniques in the electrodes.

\section{Brief overview of SOFC electrode materials}

\subsection{SOFC cathodes}

Despite the high total (electronic and ionic) conductivity of LSM, its poor oxide ion conductivity rather limits the active sites for the oxygen reduction reaction (ORR) to be confined mainly to the triple-phase boundary (TPB) sites. Hence, the electrochemical performance of a cathode fabricated by depositing a layer of LSM onto a dense YSZ electrolyte is mainly dictated by the number of active contact sites of LSM and the YSZ electrolyte. An idea to enlarge the electrochemically active area is to extend the electrolyte through the whole thickness of the LSM layer. Thus, attempts have been made to use a composite of LSM and YSZ, as the cathode in SOFCs (Fig. 1). Several studies have demonstrated that the area specific polarization resistance (ASR) for the ORR of a pure LSM cathode is significantly higher than that of LSM-YSZ composite cathodes. ${ }^{13-16}$ Apart from the extension of the electrochemically active region, the use of composites can enhance the electrode microstructural stability and also improve mechanical properties due to better adherence to the YSZ electrolyte. ${ }^{17}$

Reduction in the overall electrode polarization resistance for the ORR can be made further by replacing YSZ with an electrolyte material of higher oxide ion conductivity such as Gd-doped ceria (CGO), $\mathrm{Sr}$ and $\mathrm{Mg}$-co-doped $\mathrm{LaGaO}_{3}$ (LSGM), and LSM with more electrochemically active mixed ionic and electronic conductors (MIECs). In MIECs, the oxygen exchange could occur at a larger surface of the material due to its appreciable amount of oxygen vacancies $\left(V_{\mathrm{O}}^{*}\right)$ and faster oxide ion transport within the cathode material.

To date, the well-known MIECs, including perovskite-type structure $\mathrm{La}_{1-x} \mathrm{Sr}_{x} \mathrm{Co}_{1-y} \mathrm{Fe}_{y} \mathrm{O}_{3-\delta}$ (LSCF) and $\mathrm{Ba}_{1-x} \mathrm{Sr}_{x} \mathrm{Co}_{1-y} \mathrm{Fe}_{y} \mathrm{O}_{3-\delta}$ (BSCF) and layered double perovskite-type $\mathrm{LnBaCo}_{2} \mathrm{O}_{5+\delta}$ are being explored as cathodes for next generation SOFCs. ${ }^{18,19}$ Several groups have demonstrated that the electrochemical performance of porous LSCF cathodes is superior to that of conventional LSM cathodes. ${ }^{20,21}$ It should be noted that MIECs generally have high activation energy for oxygen self-diffusion compared to oxide ion electrolytes such as $\mathrm{Ce}_{0.9} \mathrm{Gd}_{0.1} \mathrm{O}_{1.95}$ (CGO) and LSGM; thus, their ionic conductivity drops sharply with decreasing temperature. For example, the activation energy for oxygen tracer diffusion $\left(E_{\mathrm{A}, \mathrm{D}^{*}}\right)$ in $\mathrm{La}_{0.6} \mathrm{Sr}_{0.4} \mathrm{CoO}_{3-\delta}$ is $176 \mathrm{~kJ} \mathrm{~mol}^{-1}$ while that for CGO is $87 \mathrm{~kJ} \mathrm{~mol}^{-1} .^{22,23}$ Thus, the addition of high ionic conducting CGO is advantageous for reduced temperature operation. The presence of the solid electrolyte phase in the cathode should serve to enhance the chemical compatibility of the electrode with the electrolyte by improving the adhesion and matching the thermal expansion coefficient (TEC) of the materials. Thus, composite cathodes are generally favored over singe-phase MIECs, even though there is a significant decrease in the electrochemically active surface area of electrodes.

Exploration of other electrolyte and cathode materials may also reduce the energy losses from ohmic resistance and activation polarization resistance. In the case of the ionic conducting component, there are several materials with higher ionic conductivity than YSZ that can be considered, ${ }^{27-34}$ including fluorite-type $\mathrm{Ce}_{0.9} \mathrm{Gd}_{0.1} \mathrm{O}_{1.95}$ (CGO), perovskite-type $\mathrm{Ba}_{2} \mathrm{In}_{2} \mathrm{O}_{5}, \quad \mathrm{Ba}_{2} \mathrm{In}_{1.75} \mathrm{Ce}_{0.25} \mathrm{O}_{5.125}$, and $\mathrm{La}_{0.9} \mathrm{Sr}_{0.1} \mathrm{Ga}_{0.9} \mathrm{Mg}_{0.1} \mathrm{O}_{3}$ (LSGM) ${ }^{24}$ and layered structure $\mathrm{Bi}_{2} \mathrm{VO}_{5.5}, \mathrm{Bi}_{2} \mathrm{Sr}_{2} \mathrm{Nb}_{2} \mathrm{GaO}_{11.5}$, and $\mathrm{Bi}_{2} \mathrm{~V}_{0.9} \mathrm{Cu}_{0.1} \mathrm{O}_{5.35}$ (BICUVOX ${ }^{25}$ (Fig. 2). ${ }^{32-34}$ However, some of these other oxide ion electrolyte systems show several disadvantages. For example, LSGM suffers from significant reactivity with perovskite-type structure LSM, LSCF and BSCF electrodes under oxidizing conditions and forms secondary phases in the course of processing. ${ }^{26,27}$ Bismuth-based oxides are known for their poor thermodynamic stability under reducing atmospheres (e.g., SOFC anode). Doped bi-oxides with MIECs or metals could be used as cathodes in oxidizing atmospheres at intermediate temperatures. Furthermore, doped $\mathrm{Bi}_{2} \mathrm{O}_{3}$ has been used with doped ceria as a bi-layer membrane for intermediate temperature SOFCs. ${ }^{28-31}$ Ceria exhibits relatively easy reducibility at low $p_{\mathrm{O}_{2}}$ leading to the increase in electronic conductivity at elevated temperatures. Therefore, the operating temperature should be kept below $700{ }^{\circ} \mathrm{C}$, if doped ceria is used as the electrolyte to avoid a significant reduction of open circuit voltage (OCV) due to the electronic conduction. However, if these materials are maintained under oxidizing conditions, such as in a SOFC cathode, there appear to be no issues even at higher temperatures. Thus, ceria appears to be the most promising composite material in a SOFC cathode in terms of thermo-mechanical stability and reactivity with common perovskite-type transition metal oxide-based cathodes.

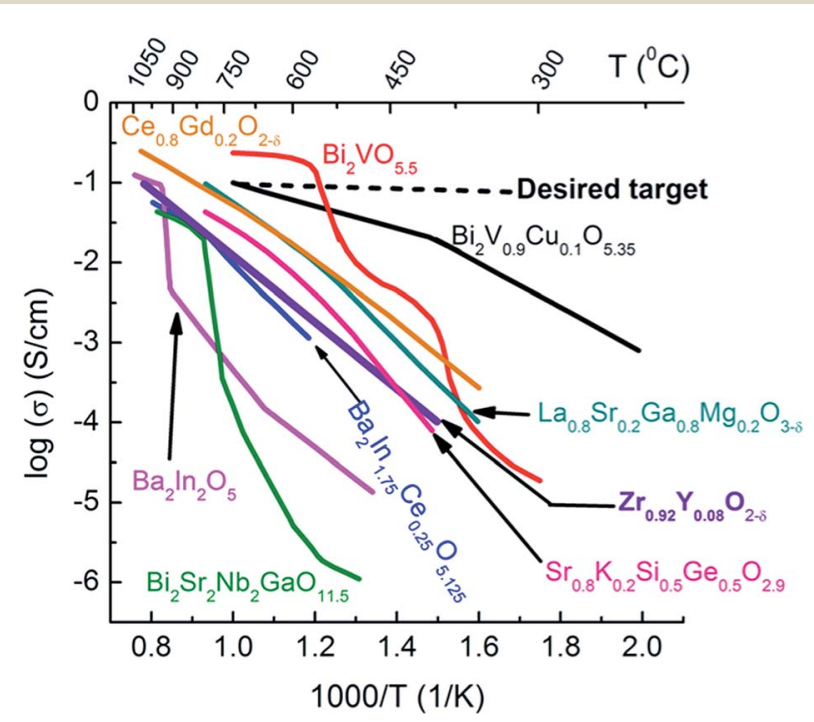

Fig. 2 Oxide ion conductivities of some solid electrolytes. ${ }^{32-34}$ 
To ensure the high durability in a SOFC, a careful choice of components for a composite cathode should be made based on chemical and thermo-mechanical compatibility with the electrolyte. ${ }^{35}$ Cobaltite- and ferrite-based electrodes are not being used as composites due to their poor matching TEC with conventional electrolyte YSZ. A number of studies have demonstrated that highly ionic conducting electrolytes, with MIEC ceramics or metals, can be utilized as cathode materials to improve electrochemical performances. For example, Xia and Liu demonstrated that BICUVOX can be effectively employed in a composite cathode with $\mathrm{Ag}$ (57 wt\%) as the electronic conducting component. ${ }^{36}$ This composite cathode showed a remarkable performance of $0.53 \Omega \mathrm{cm}^{2}$ at $500{ }^{\circ} \mathrm{C}$ using CGO as an electrolyte. Several optimization studies have been performed for different composite cathodes and found that the optimum amount of solid electrolyte component falls within 30-60 wt\%. ${ }^{17}$ The addition of more electrolytes results in an increase in ORR ASR due to a decrease in the amount of electrocatalysts.

\subsection{SOFC anodes}

Some of the ideas in the SOFC cathode research have been applied in the case of SOFC anode development. In the case of anodes, Ni has been known to be a good catalyst for the hydrogen oxidation reaction (HOR). However, pure Ni tends to aggregate at high temperatures. The addition of an oxide component such as YSZ not only solves the aggregation problem, as first recognized by Spacil, ${ }^{37}$ but also improves the electrochemical performance of the anode. ${ }^{\mathbf{1 0}}$ Indeed, Ni/YSZ anodes are robust, easy to fabricate, and highly efficient for the electrochemical HOR and electrochemical oxidation of syngas. ${ }^{38}$ For the targeted commercial application, however, it is highly desirable that the anode can be fed directly with hydrocarbon fuels such as natural gas. Unfortunately, $\mathrm{Ni}$ is also a good catalyst for the decomposition of hydrocarbons to form carbon deposits in the anode surface, which block the gas access in electrochemical reaction zones. Another problem, when using hydrocarbon fuels, is the presence of sulfur as impurity, which exists as gaseous $\mathrm{H}_{2} \mathrm{~S}$ after reforming. Ni-based SOFC anodes have a very low level of tolerance towards sulfur poisoning. ${ }^{10,39}$ Finding alternatives to Ni/YSZ anodes is the focus of many recent studies that aim at directly utilizing hydrocarbon fuels in SOFCs.

The long-term global challenge is to replace the Ni-YSZ cermet anode with alternative $\mathrm{H}_{2} \mathrm{~S}$ and coke stable MIEC ceramics for advanced SOFCs. The presence of ionic conductivity would also serve to enhance the effective size of TPBs. Indeed, in recent studies, the enlargement of the active surface in MIECs was reported in fluorite-type ceria using in situ X-ray photoelectron spectroscopy (XPS). ${ }^{40}$ A change of the $\mathrm{Ce}^{3+/ 4+}$ valence state in the electrode upon a bias voltage was a span of $100 \mu \mathrm{m}$ from the current collector, suggesting that the whole ceria surface could be electrochemically active for the HOR. Chueh et al. also demonstrated that the 'near-equilibrium' HOR pathway on ceria-based electrodes is only dominated by electrocatalysis at the MIEC oxide/gas interface, as shown in their electrochemical impedance spectra (EIS) using welldefined pattern electrodes. ${ }^{\mathbf{4 1}}$ Nonetheless, the effective surface area of other MIEC anodes is yet to be deeply investigated. Over the last two decades, a large number of promising MIECs, including $\mathrm{Ce}_{1-x} \mathrm{M}_{x} \mathrm{O}_{2-\delta}(\mathrm{M}=\mathrm{Ni}, \mathrm{Cu}), \mathrm{La}_{1-x} \mathrm{Sr}_{x} \mathrm{Cr}_{1-y} \mathrm{Mn}_{y} \mathrm{O}_{3}$, and $\mathrm{BaZr}_{0.1} \mathrm{Ce}_{0.7} \mathrm{Y}_{0.2-x} \mathrm{Yb}_{x} \mathrm{O}_{3-\delta}$, have been shown to have excellent electrochemical performance under impure fuel conditions. ${ }^{\mathbf{4 2 , 4 3}}$ The design strategies of next generation SOFC anodes were recently reported..$^{3,7,8,44}$

\section{Emerging SOFC electrode engineering techniques}

Not only the electrode material chemical composition, but also the electrode engineering is equally important to optimize the transport of electrons, gases, and ions in the electrode layer. Electrode engineering parameters include the processing parameters such as temperature, sintering duration and atmosphere, which determine the final microstructure and chemical composition of the electrode. The choice of techniques commonly depends on the cell design, which can be tubular, planar, and more recently, "micro-fabricated". ${ }^{45-49}$

The common way to prepare cathodes in a planar design, particularly in an anode supported SOFC, is to deposit the cathode after preparing the anode/electrolyte assembly, using slurry coating, screen printing, tape casting, and wet powder spraying methods. ${ }^{50}$ In these methods, the thickness of the deposited layer after sintering is usually several micrometers. The sintering temperature is a compromise between the formation of sufficient connection between the electrode and the electrolyte and the prevention of solid-state reactions between the components of the cathode and the electrolyte. Sometimes, the sintering temperature range is very narrow such that the choice of materials for a two-phase combination is very limited. For example, it may be thought that a material can replace LSM in the LSM-YSZ composite with a superior electrocatalytically active Sr-doped $\mathrm{LaCoO}_{3}$ (LSC) cathode. However, at temperatures above $1000{ }^{\circ} \mathrm{C}$, it is known that LSC reacts with YSZ. ${ }^{51,52}$ A firing temperature lower than $1000{ }^{\circ} \mathrm{C}$ may be attempted to fabricate a LSC-YSZ composite cathode, but the resulting cathode would not be optimal as YSZ requires about $1000{ }^{\circ} \mathrm{C}$ to attain sufficient connection of grains. ${ }^{53}$

The surface areas of cathodes prepared by conventional methods are normally low; hence they exhibit a high ASR at low operating temperatures. This drawback has initiated great interest in nano-scaled electrodes, which possess an inherently large electrochemically active surface area. Generally, there are three ways to prepare nano-sized particle electrodes for SOFCs namely, thin-film deposition, infiltration, and ex-solution (Fig. 3) ${ }^{54}$

\subsection{Thin-film deposition}

In the conventional thin-film deposition method, the cathode is deposited on a dense solid oxide ion electrolyte substrate (Fig. 3b). The thicknesses of electrodes attained in this method range typically from the submicron to several micrometer level, and they are sometimes called as "micro $(\mu)$-SOFCs". ${ }^{55}$ Most 

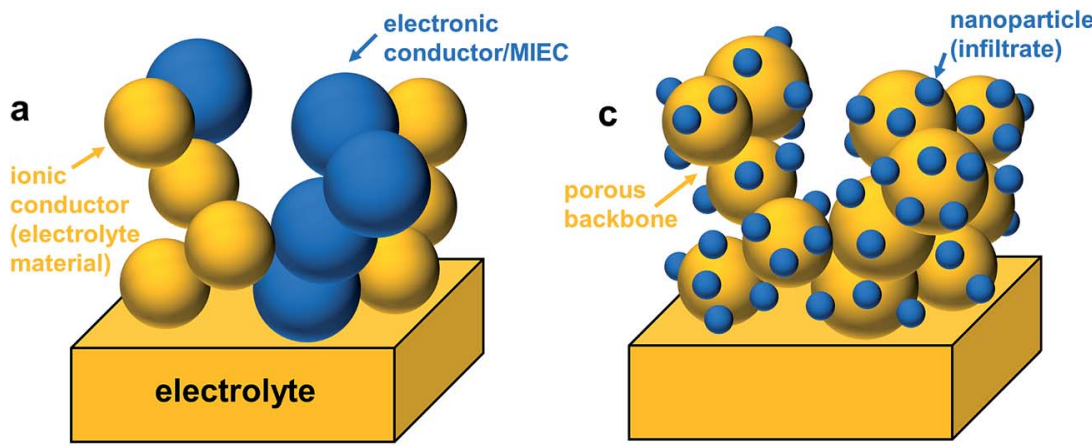

b

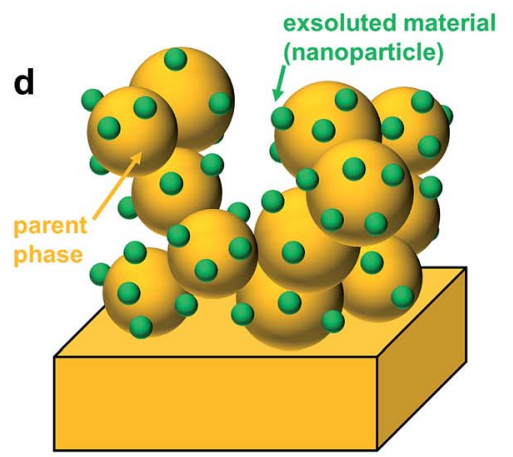

Fig. 3 Schematic of various SOFC electrode preparation techniques: (a) composite electrode formed via a conventional ceramic processing method, (b) thin-film deposition, (c) infiltration, and (d) ex-solution.

relevant thin-film deposition techniques for SOFC/SOEC applications include vacuum deposition (for e.g., physical vapor deposition (PVD), chemical vapor deposition (CVD), and pulsed laser deposition (PLD)) as well as liquid precursor-based thinfilm deposition (for e.g., spray deposition, electrophoretic deposition (EPD) and spin- and dip-coating) methods. An excellent review of some of these techniques was written by Beckel et al. in 2007. ${ }^{56}$ Typical cathode materials used in $\mu$-SOFCs include Pt, LSC, LSCF, and BSCF. ${ }^{56}$

In the work of Dieterle et al., a dip coating technique was employed to obtain nano-porous $\mathrm{La}_{0.6} \mathrm{Sr}_{0.4} \mathrm{CoO}_{3-\delta}$ thin films with the thickness in the range of $150-200 \mathrm{~nm} .{ }^{57}$ ORR ASR $\left(R_{\mathrm{p}}\right)$ of $0.023 \Omega \mathrm{cm}^{2}$ at $600{ }^{\circ} \mathrm{C}$ was reported.$^{57}$ However, a significant degradation of performance (ASR increased to $0.069 \Omega \mathrm{cm}^{2}$ at $600{ }^{\circ} \mathrm{C}$ ) was observed after $100 \mathrm{~h}$. Employing the spray pyrolysis technique, Darbandi et al. obtained an ORR ASR $\left(R_{\mathrm{p}}\right)$ of $0.038 \Omega$ $\mathrm{cm}^{2}$ at $600{ }^{\circ} \mathrm{C}$ for nano-porous $\mathrm{La}_{0.25} \mathrm{Ba}_{0.25} \mathrm{Sr}_{0.5} \mathrm{Co}_{0.2} \mathrm{Fe}_{0.8} \mathrm{O}_{3-\delta}$ thin films $(\leq 1 \mu \mathrm{m}),{ }^{58}$ but with no detail discussed on the stability. The use of the thin-film deposition method is promising but there are several issues such as optimization of the electrode microstructure, substrate choice and component durability that need to be addressed before commercialization..$^{59}$ A summary of electrochemical performances of selected SOFC electrodes prepared using various preparation techniques is shown in Table $1 .^{13,18,54-56,60-66}$

\subsection{Infiltration technique}

The fabrication of SOFC components via infiltration has been widely employed in recent years and several excellent reviews have already been published. ${ }^{10-12,38,53,67,68}$ The present article aims to highlight nano-/microstructuring strategies that are related to infiltration and show opportunities with this technique. In general, in an infiltration technique, a liquid solution usually composed of dissolved metal nitrates is introduced into a pre-formed porous backbone, followed by drying and calcination to produce the desired oxide phase (Fig. 3c). The infiltrated material can form either discrete nanoparticles or a thin continuous network on the surface of the electrolyte backbone. ${ }^{12}$ Capillary forces enable the incorporation of the infiltrate into the porous backbone, through vacuum assisted infiltration. ${ }^{54,69}$

A schematic of the infiltration procedure is shown in Fig. 4. Here, the backbone can be inherently functional or skeletal as classified in the recent review by Ding et al. ${ }^{67}$ Inherently, functional backbones would include a single-phase MIEC or a composite of an electrolyte and an electronic conductor. Skeletal backbones are ionic conducting scaffolds such as YSZ, CGO and LSGM. Depending on the combination of the infiltrate and the backbone material, infiltration into the as-sintered backbones is performed to increase catalytic activity and ion and electron conductivity. ${ }^{12}$

Compared to the conventional composite method, the major advantage of the infiltration technique is that nanoparticles of the catalyst can be established resulting in highly enlarged zones of electrocatalytic materials. By employing a skeletal backbone of ionic conducting scaffolds, the electrode process offers a lower ASR. The bulk oxygen ion conductivity of the ionic conducting backbone is much higher than that of the MIEC, which allows the electrochemically active thickness of the electrode to be spread out further in the electrode, and thus, 


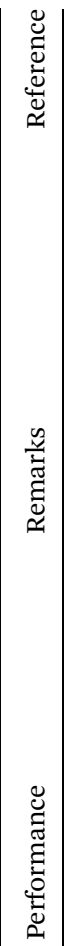

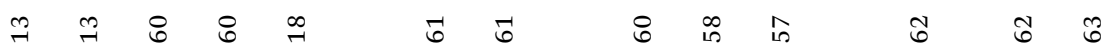

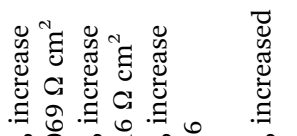

ป

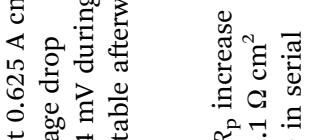

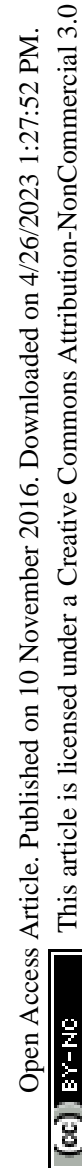

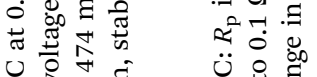

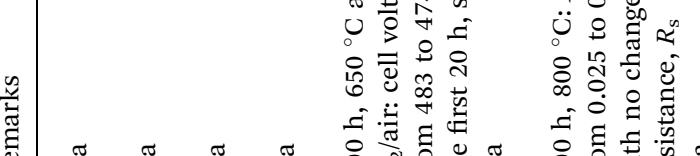

至

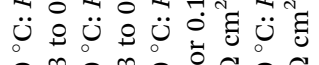

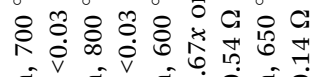

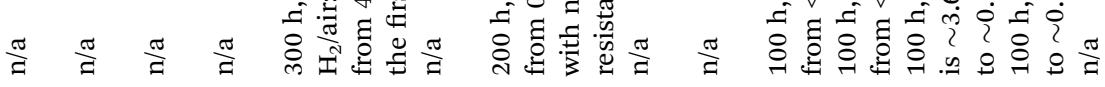

ర6

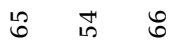

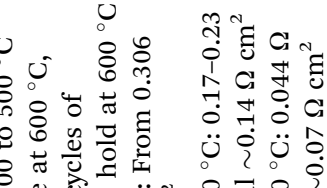

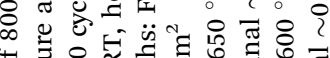

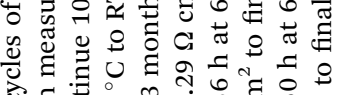

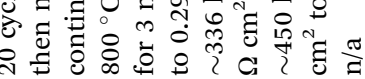

0

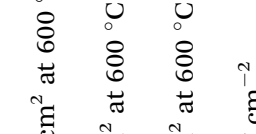

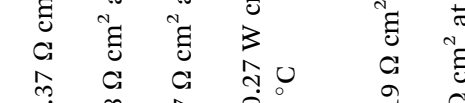

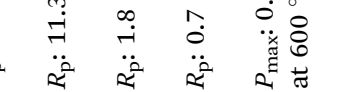

से थे थं है

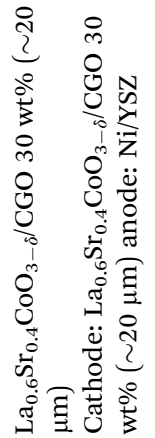

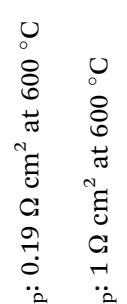

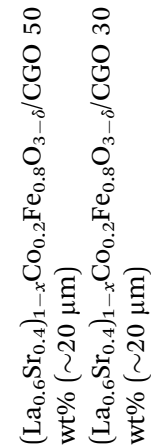

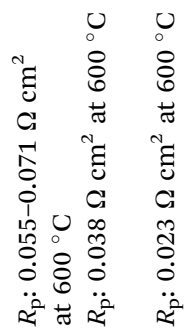

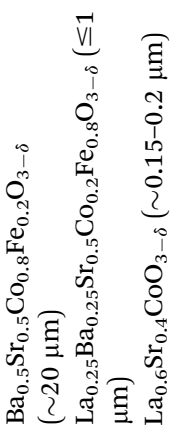

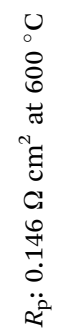

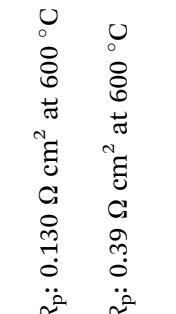

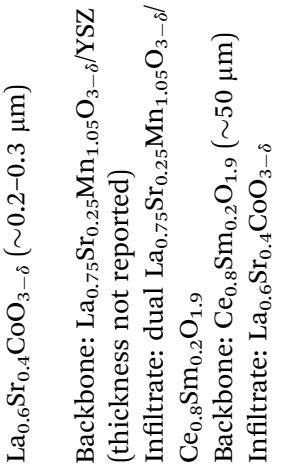

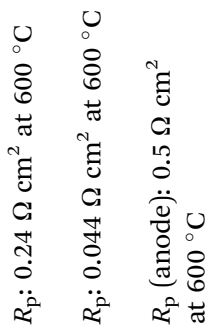

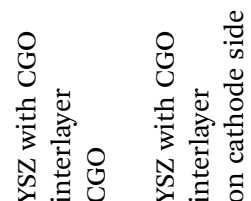

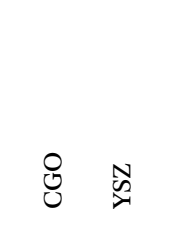

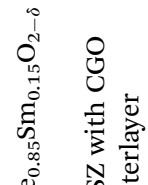

N $\begin{aligned} & \text { N } \\ & \text { N }\end{aligned}$
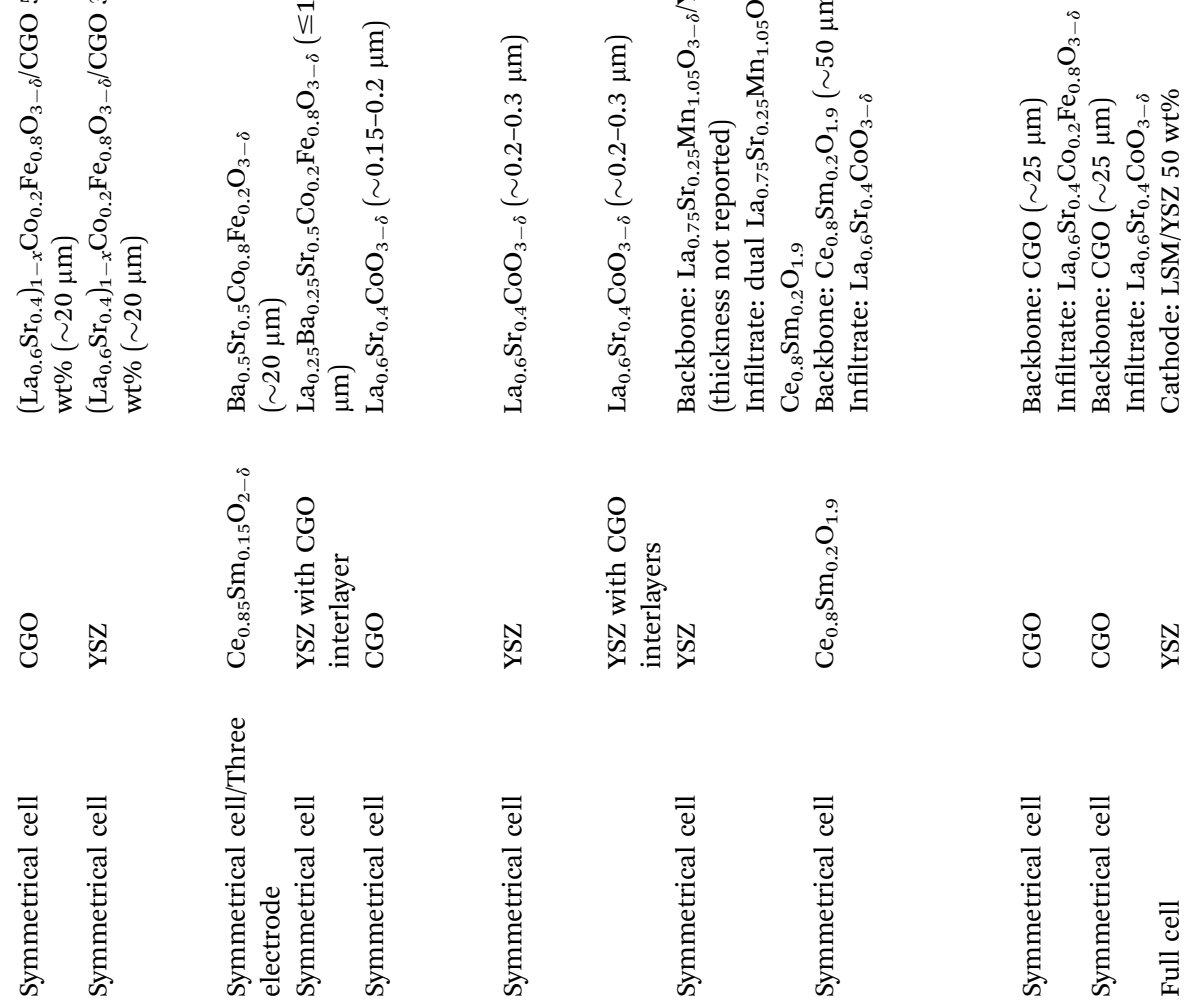

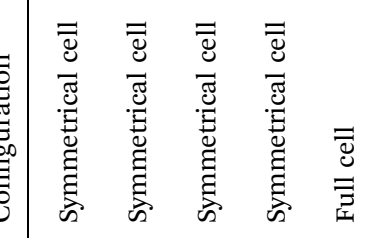

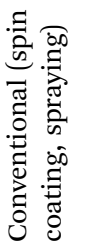
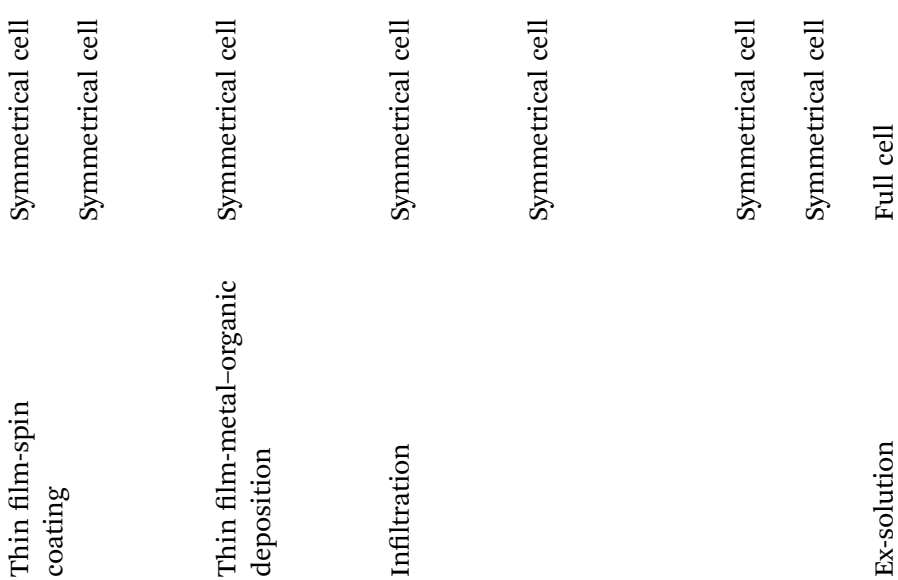


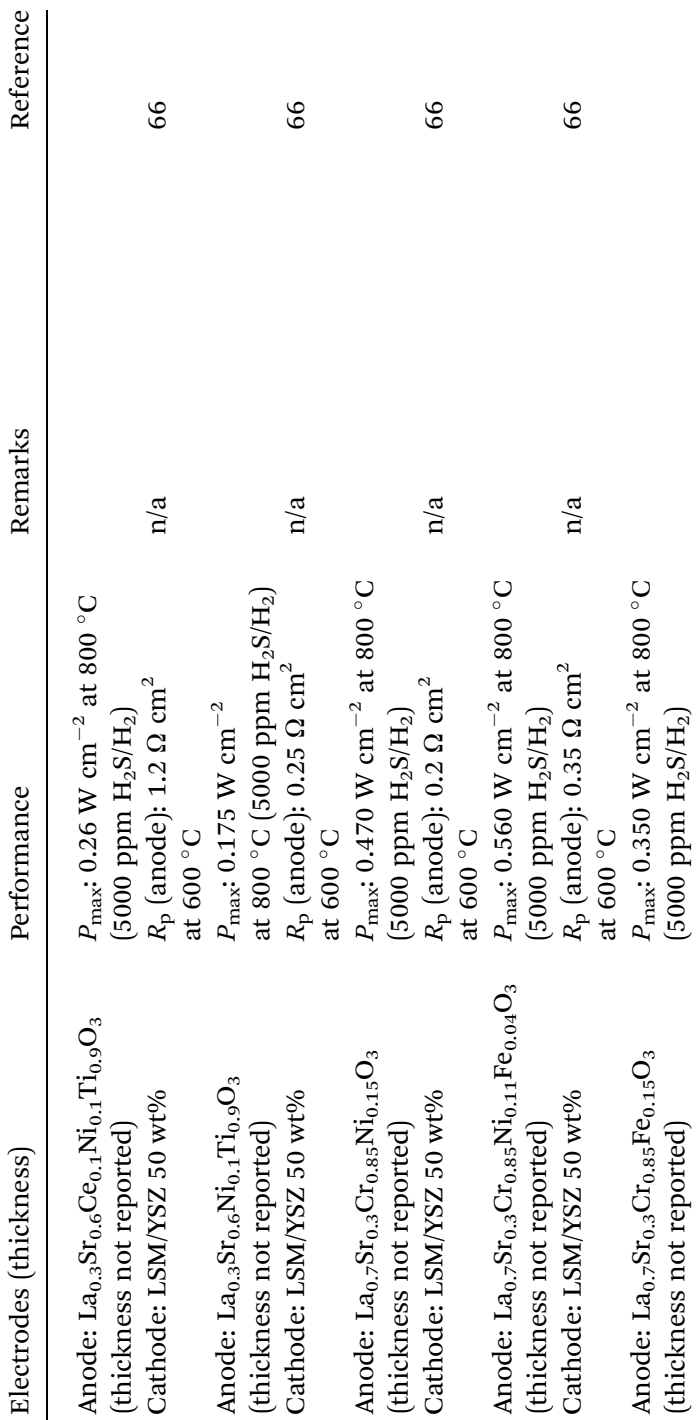

significantly increases the catalytically active surface area. In addition, infiltration can be independent of other sintering steps, and such a process can be integrated on electrodes prepared by conventional methods including screen-printing, tape casting and spraying. The possible chemical reactions between the infiltrated and backbone phases are also minimized because of the low calcination temperature involved. This could also mean that a wider variety of catalyst materials can be employed which cannot be otherwise used in the conventional composite electrodes. Specific trends in infiltration are discussed more thoroughly in the succeeding section.

The infiltration method has shown improved electrochemical performance for a variety of candidate materials. Especially for SOFC cathodes, several combinations including perovskite/YSZ and perovskite/ceria, especially lanthanum cobaltite-based perovskite/ceria combinations, have been studied. ${ }^{10,38,67}$ To date, three approaches, namely morphological control, core shell structure formation, and multi-component/ multiphase infiltrates, have been used to obtain functional nanostructured electrodes with high electrochemical activity for SOFCs. A schematic of these three approaches is shown in Fig. 5.

3.2.1 Morphological control. One of the common goals of many researchers is to prepare nanostructured electrodes with a high surface area and controlled morphology. Infiltration combined with low temperature sintering processes leads to the formation of nanostructured catalysts. The nanostructured catalysts prepared by this method have significantly increased the triple-phase boundary (TPB) and surface area for the oxygen surface exchange reaction. Characteristic to morphological control is taking advantage of the properties of the nanostructured catalysts together with the avoidance of inter-diffusion of the elemental components of the infiltrate material and the backbone that could result in the loss of electro-catalytic properties and formation of undesirable secondary phases during the fabrication of the cathode and also during the operation..$^{67,76,77}$ With this strategy, there are at least two schemes, engineering the infiltrate solution and engineering the electrolyte/electrode backbone that can be followed to obtain not only the desired performance enhancement, but also the improvement of long-term stability of the electrodes.

The physical properties and composition of the infiltrate solution can greatly affect the morphology of the catalyst or the infiltrate. Fig. 6 shows an example of the varying microstructures depending on the nature of the infiltrate precursor solution. Thus, engineering or finding the right combination of the components of the infiltrate precursor solution is very important for SOFC electrodes. Usually, the infiltration precursor solution consists of a solvent, surfactant, and metal nitrates. The purpose of the surfactant is to not only form complexes with metal cations to assist the formation of a crystalline phase but also to control the particle size through suitable micelles. ${ }^{78,79}$ Typical examples of surfactants used in SOFCs are citric acid, ${ }^{67,78,80}$ Triton X-series, ${ }^{78,79,81}$ and co-polymers. ${ }^{77,82}$ In addition to the surfactant, chelating agents/dispersants are added to the infiltrate. They effectively separate the cations, thereby improving mixing of the cations in the infiltrate 

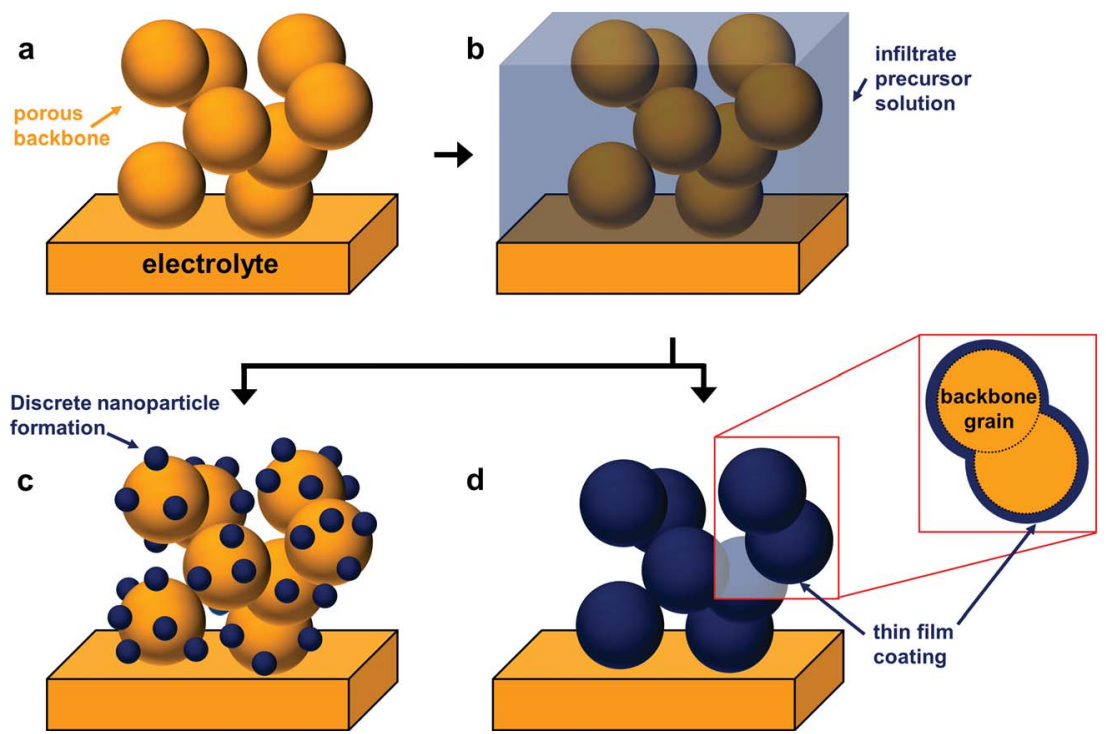

Fig. 4 Schematic showing the infiltration process being used in SOFC development. (a) A preformed porous backbone is infiltrated by a precursor solution of the infiltrate material. (b) Following a heat treatment to form the desired phase of the infiltrate; the distribution of the infiltrated material will either be in (c) discrete nanoparticle formation or (d) thin-film coating formation. It is possible that a configuration resembling a mix of (c) and (d) can be formed.

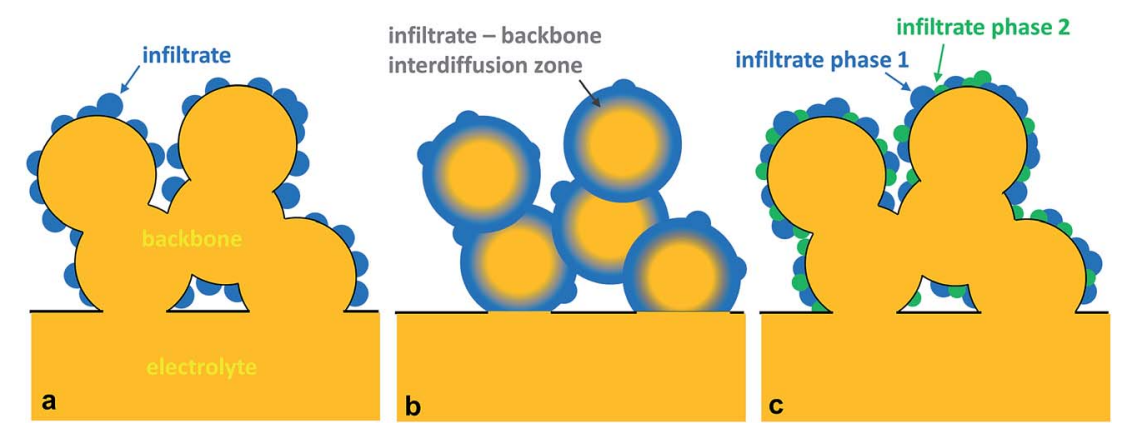

Fig. 5 Schematic of the three approaches based on infiltration that can be employed to obtain improved electrodes: (a) morphological control, (b) core-shell, and (c) multi-component/multi-phase infiltrates.

precursor solution. Problems such as inhomogeneous dispersion of catalyst crystals into the porous host and impurity phase formation, when the infiltrate solution consists of more than 3 elements, can be mitigated by the addition of dispersants to the infiltrate.

The viscosity of the infiltrate solution is subject to change by all of the constituents of the infiltrate precursor solution. Van Dillen et al. have found non-uniform distribution of derived catalysts when the infiltrate has a high viscosity. ${ }^{83}$ Jiang et al. have shown a more uniform catalyst layer when low viscosity infiltrate precursor solution was used. ${ }^{84} \mathrm{~A}$ disadvantage of low viscosity is that a large number of infiltration cycles are needed to introduce a sufficient amount of catalysts. Increased surfactant and/or metal cation concentration effectively increases the viscosity. An advantage of increased metal cation concentration is that the number of infiltration cycles could be reduced. Sholklapper et al. attempted a single-step infiltration using a concentrated LSM nitrate precursor solution with a commercial polymeric surfactant (Triton-X100) and shown that it is possible to form a thin layer of a continuous network of nanostructured LSM on an YSZ backbone. ${ }^{79}$ A problem though with highly viscous and concentrated infiltrate solution is penetration in the porous structure. ${ }^{\mathbf{1 0}}$ Researchers are continually tackling the task of improving the infiltrate solution to obtain uniformly distributed and phase pure catalysts which is not time consuming and does not hinder its practical application in SOFCs.

The other scheme to influence the morphology of the catalyst layer using the infiltration technique is to engineer the backbone. A typical backbone for infiltration is designed to have a very high porosity to provide easy penetration of the infiltration solution and transport of gas species once it is utilized as an electrode. One of the best examples of backbone microstructure engineering is from the study of Küngas et al. where an YSZ backbone is etched with hydrofluoric acid to maximize the TPBs. ${ }^{85}$ Fig. 7 shows a comparison of the resulting microstructures from HF etching of the YSZ backbone to control the morphology of the infiltrated electrode. ${ }^{85}$ Many studies were 

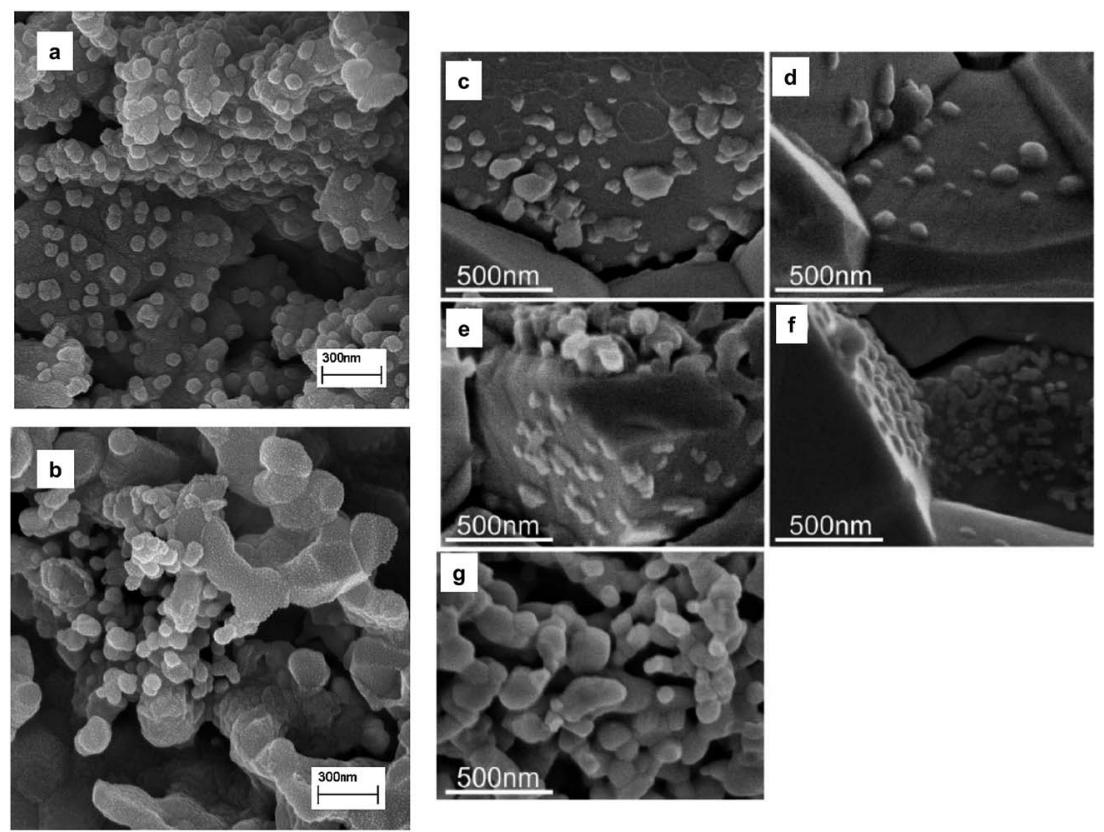

Fig. 6 Examples of the infiltrate showing different microstructures based on infiltration solutions (a) $1.44 \mathrm{M} \mathrm{Sm}_{0.5} \mathrm{Sr}_{0.5} \mathrm{CoO}_{3}$ (SSC) nitrate solution with water : ethanol volume ratio $(1: 0.6){ }^{78}$ (b) $1.44 \mathrm{M} \mathrm{SSC}$ nitrate solution (without ethanol) $7^{78}$ (c) pure nitrate derived $0.5 \mathrm{M} \mathrm{SSC}$ (electrode/ electrolyte interface), ${ }^{81}$ (d) triton X-derived $0.5 \mathrm{M} \mathrm{SSC}$ (electrode/electrolyte interface), ${ }^{81}$ (e) citric acid derived $0.5 \mathrm{M} \mathrm{SSC}$ (electrode/electrolyte interface), ${ }^{81}$ (f) triton X-derived 0.293 M SSC (electrode/electrolyte interface), and (g) citric acid derived 0.5 M SSC (within electrode). ${ }^{81}$ Reprinted with permission.

reported to understand the effect of morphology on electrochemical performance but a simple enlargement of the surface area for the oxygen surface exchange reaction could not explain the enhancement. ${ }^{54,57,86,87}$

3.2.2 Core-shell structure electrodes. Many of the research studies aim to form the desired phase of the infiltrated material at the lowest possible temperature to avoid potential chemical reaction between the backbone electrolyte and infiltrate material. The common reaction products that form between the backbone and infiltrate at high temperatures usually exhibit poor electronic or ionic conductivities compared to either of the backbone or the infiltrate material. For example, the MIEC, $(\mathrm{La}, \mathrm{Sr})(\mathrm{Fe}, \mathrm{Co}) \mathrm{O}_{3-\delta},{ }^{\mathbf{6 1 , 8 8 - 9 0}}$ has been investigated intensively due to its excellent catalytic activity for the ORR and a combination of high electronic and oxide ion conductivity and makes it as a very good candidate for infiltration. However, these types of materials are also known for their high chemical reactivity with zirconia-based electrolytes, where the most common result is the formation of electronically insulating $\mathrm{La}_{2} \mathrm{Zr}_{2} \mathrm{O}_{7}$ and $\mathrm{SrZrO}_{3}$. It has also been reported that $\mathrm{La}_{0.6} \mathrm{Sr}_{0.4} \mathrm{CoO}_{3}$ undergoes a solidstate reaction with YSZ at temperatures as low as $700{ }^{\circ} \mathrm{C} .{ }^{91}$ If these types of materials are still desired to be infiltrates in zirconia, an interlayer material that is not reactive to both the zirconia based backbone and $(\mathrm{La}, \mathrm{Sr})(\mathrm{Fe}, \mathrm{Co}) \mathrm{O}_{3-\delta}$ could be considered.

Inter-diffusion of the elemental components of the infiltrate and backbone material to form new compound(s) or a gradient of inter-diffused elements at the interface could be beneficial, if a material with superior electrical/electrochemical properties and an electrode with highly improved electrochemical activity with increased morphological stability can be obtained. Increased morphological stability may be inferred from the resulting new microstructure, as shown schematically in Fig. 7b. Essentially, a thin-film running through the entire grain of the backbone can form a continuous network of the necessary catalyst for ORR and HRR. The problem of possible discontinuity among the infiltrate through grain-growth and particle segregation at elevated temperatures could be avoided using this method. Several studies have exploited this idea of forming highly active surfaces due to the migration of species in the infiltrate or the backbone material. An example of this kind of electrode is the diffusion of Mn from LSM electrodes to YSZ surfaces. ${ }^{92,93}$

The idea of a core-shell structure to take advantage of the desirable physical properties of the reacted entities between the backbone and infiltrate is shown recently by Chen et al. ${ }^{94}$ Here, a core-shell electrode composed of a $\mathrm{Sm}_{0.2} \mathrm{Ce}_{0.8} \mathrm{O}_{1.9}$ (SDC) scaffold electrolyte, and a MIEC, Sm, Ce-doped $\mathrm{SrCoO}_{3-\delta}$, was formed from solution infiltration in combination with high temperature reactive sintering (Fig. 8a). ${ }^{94}$ The concept of the core-shell structure between $\mathrm{SrCoO}_{3-\delta}$ (SC) and SDC was utilized to develop a high performance SOFC cathode. ${ }^{95} \mathrm{SC}$ is unstable and is a moderate electrocatalyst for the ORR. A and/or B-site doping in SC is usually performed to stabilize the perovskite phase structure and increase its ionic and/or electronic conductivity. ${ }^{94,96,97}$ In the study by Zhou et al., ${ }^{95} \mathrm{SC}$ and SDC powders were mixed and fired at varying temperatures. XRD confirmed the chemical reaction between the SC and SDC; specifically, the formation of a cubic lattice structure in the reacted powder was attributed to the incorporation of Ce into 


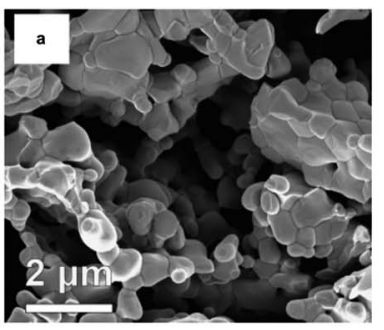

b untreated YSZ:
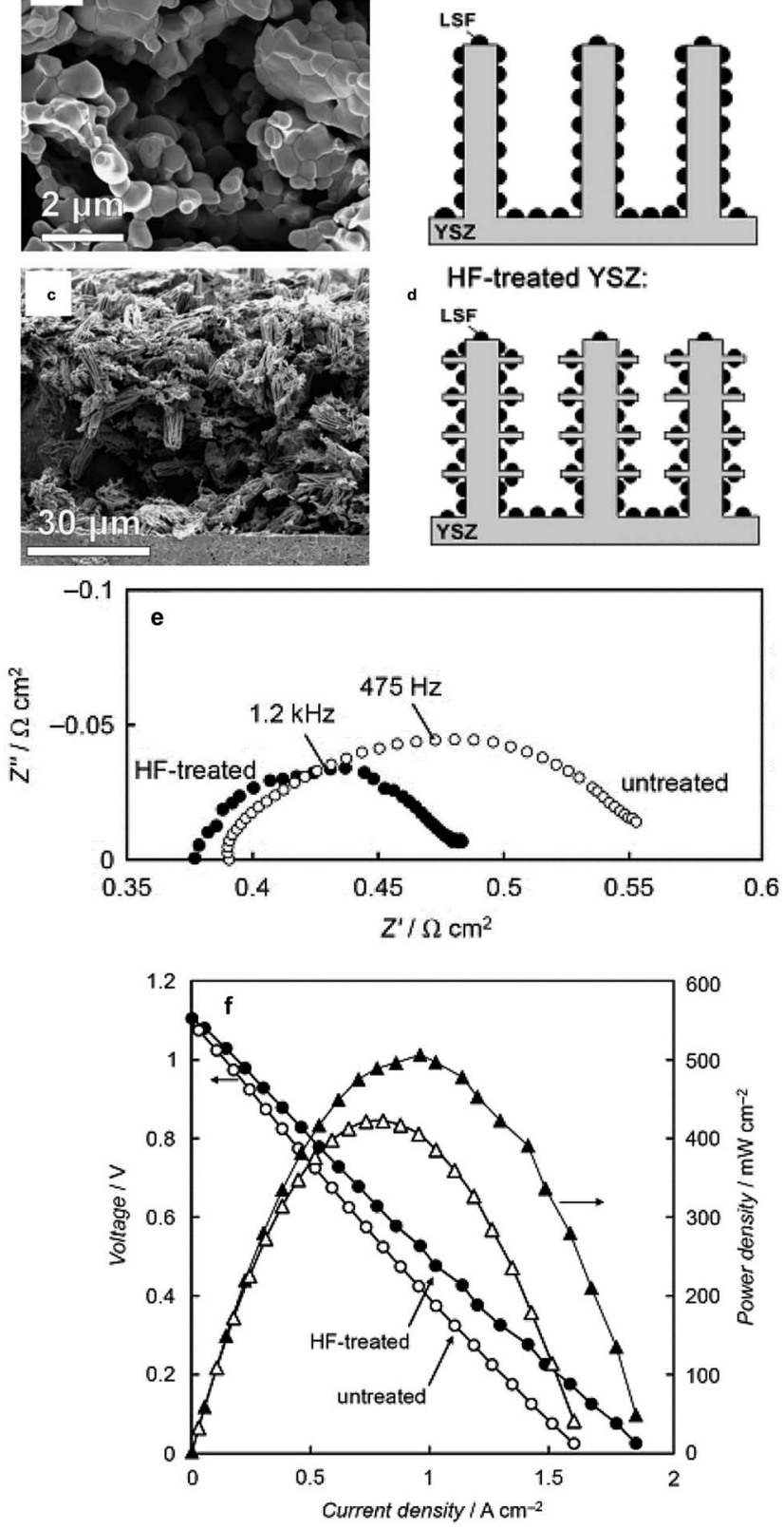

Fig. 7 Example of backbone engineering from Küngas et al. ${ }^{85}$ (a) YSZ backbone before HF etching, (b) schematic of untreated YSZ, (c) YSZ after HF etching, (d) schematic of the HF etched-YSZ backbone, (e) impedance comparison of full cells with untreated and HF-treated backbone (LSF infiltration) cathode and $\mathrm{Pd}-\mathrm{CeO}_{2}$ anode in humidified $\left(3 \% \mathrm{H}_{2} \mathrm{O}\right) \mathrm{H}_{2}$ and (f) the corresponding I-V and power dens lity curves of the fuel cell. Reprinted with permission.

the B-site of perovskite-type SC. The evidence of the formation of a high electronic conductivity phase was inferred from the fact that the electronic conductivities of the SC + SDC composite sintered at $1000{ }^{\circ} \mathrm{C}$ have reached $c a .100-200 \mathrm{~S} \mathrm{~cm}^{-1}$ at 300$900{ }^{\circ} \mathrm{C}$ in air, while that of pristine SC showed $5-25 \mathrm{~S} \mathrm{~cm}^{-1}$. The reaction between SC and SDC was also found to have improved ionic conductivity compared to the negligible ionic conductivity of the SC.
Chen et al. ${ }^{94}$ performed infiltration of SC onto SDC scaffolds followed by reactive sintering $\left(>900{ }^{\circ} \mathrm{C}\right.$ for $\left.2 \mathrm{~h}\right)$. TEM results, as shown in Fig. 8b, confirm a core-shell structure with the core part seen as a darker area and the shell part seen as a brighter area with a thickness less than $100 \mathrm{~nm}$. The electrochemical performance of an anode supported SOFC with the core-shell structured cathode exhibited much better electrochemical performance compared to SOFCs with a single-phase mixed conducting electrode or normal composite electrode (Fig. 8c).${ }^{94}$ It was also shown that such an electrode is very stable (Fig. 8d). Formation of core-shell structures offers great promise in obtaining electrodes with improved electrochemical performance and enhanced thermal stability. With the ease of fabrication and firing using the infiltration method, it would be no surprise to find that several research studies using the idea of a core-shell structure using various combinations of materials would emerge in the immediate future.

3.2.3 Multi-component/multi-phase infiltration electrodes. Most of the infiltrates reported in SOFCs are generally found to be a single-phase compound. However, there are several studies that reported secondary or impurity phases after firing. ${ }^{.4,81,98,99}$ The secondary phases may be viewed as detrimental to the electrochemical performance of electrodes. However, several groups have proposed that the secondary phases such as $\mathrm{SrCO}_{3}$, $\mathrm{Co}_{3} \mathrm{O}_{4}$ and $\mathrm{LaCoO}_{3}$ seem to be enhancing the overall oxygen surface exchange. ${ }^{54,86,100-102}$

In the case of cathodes for SOFCs, perhaps the first known motivation in pursuing multi-phase materials is from the identification of Sase et al., ${ }^{103}$ that the hetero-interfaces in the composite of $\mathrm{La}_{0.6} \mathrm{Sr}_{0.4} \mathrm{CoO}_{3}$ (LSC-113) and ( $\left.\mathrm{La}, \mathrm{Sr}\right)_{2} \mathrm{CoO}_{4}$ (LSC214) showed about three orders of magnitude higher oxygen surface exchange coefficient than that of single-phase LSC-113. Several studies have followed attempting to further explain the origins of such enhancement. ${ }^{\mathbf{1 0 4 - 1 0 6}}$ Employing first-principles calculation, Han and Yildiz proposed that both the anisotropic oxygen incorporation kinetics of the LSC-214 and the lattice strain in the vicinity of the interface are important contributors to oxygen-exchange reaction enhancement in the LSC-113/LSC214 system. $^{105}$ The work of Hayd et al. on LSC-113 thin-film cathodes, derived by metal organic deposition and with a nanoscaled microstructure, has shown that the presence of secondary phases such as LSC-214 and $\mathrm{Co}_{3} \mathrm{O}_{4}$ leads to significant improvement in oxygen surface-exchange properties (47 times better surface exchange coefficient than that of the bulk LSC-113). ${ }^{107}$

Mutoro et al., ${ }^{102}$ investigated the effect of adding particles of simple oxides on the surface of $\mathrm{La}_{0.8} \mathrm{Sr}_{0.2} \mathrm{CoO}_{3-\delta}$ on the oxygen reduction activity. They have found that a small amount of secondary phase (La, Co, and Sr-(hydr)oxides/carbonates) on $\mathrm{La}_{0.8} \mathrm{Sr}_{0.2} \mathrm{CoO}_{3-\delta}$ can significantly affect the electrode performances. Interestingly, Sr-decoration on top of the $\mathrm{La}_{0.8} \mathrm{Sr}_{0.2^{-}}$ $\mathrm{CoO}_{3-\delta}$ surface leads to an enhanced oxygen surface exchange coefficient, while La- and Co-decoration led to no change and reduction of the oxygen surface exchange coefficient, respectively. The enhancement in the case of Sr-decorated surfaces was attributed to the catalytically active interface regions between surface of Sr-enriched particles and the $\mathrm{La}_{0.8} \mathrm{Sr}_{0.2} \mathrm{CoO}_{3-\delta}$ surface. 

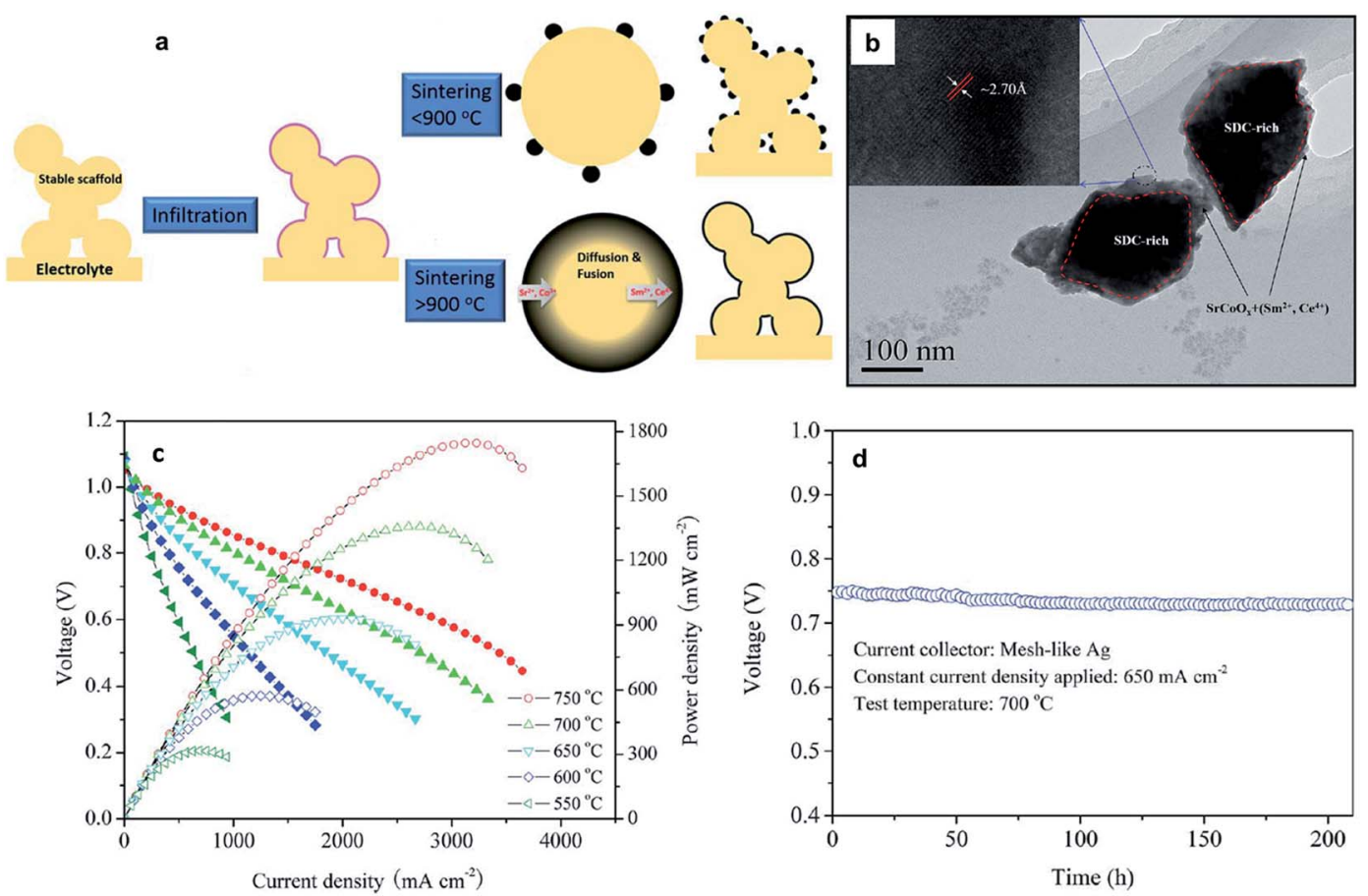

Fig. 8 (a) Schematic of the preparation for the core-shell formation derived from infiltration and reactive sintering from the work of Chen et al. ${ }^{94}$ (b) TEM of the core-shell structure (c) I-V and power density curves of cells with the Ni-YSZ anode, YSZ electrolyte, and SC infiltrated SDC cathode sintered at $1000{ }^{\circ} \mathrm{C}$ with operating temperatures from 550 to $750{ }^{\circ} \mathrm{C}$. (d) The long-term behavior of the fuel cells. Reprinted with permission.

The topic of interphase enhancement by the presence of secondary phases is an exciting area. Advancements in the nanoparticle synthesis may guide researchers on how to control the formation of such multi-phase infiltrates in actual SOFC or SOEC electrodes.

\subsection{Ex-solution method}

In the ex-solution method, catalytically active transition metals, which were first substituted in a host oxide lattice under oxidizing conditions, are released to the surface of the host oxide under reducing conditions (Fig. 3d). The incorporation of precious dopants (e.g., Ru, Pt, and $\mathrm{Rh}$ ) into the perovskites as the catalyst was reported in the 1970s. ${ }^{70}$ For example, $\mathrm{La}_{0.6} \mathrm{Sr}_{0.4} \mathrm{Co}_{0.94} \mathrm{Pt}_{0.03} \mathrm{Ru}_{0.03} \mathrm{O}_{3}$ was tested to remove simultaneously $\mathrm{HC}, \mathrm{CO}$ and $\mathrm{NO}$ from vehicle exhausts. Electron spectroscopy for chemical analysis showed a change in the valence state of the precious dopants in a reducing atmosphere. ${ }^{70}$ In 2002, Nishihata et al. demonstrated a novel catalyst of nano-sized $\mathrm{Pd}$, which was generated in situ from perovskitetype $\mathrm{LaFe}_{0.57} \mathrm{Co}_{0.38} \mathrm{Pd}_{0.05} \mathrm{O}_{3}$ (Fig. 9). ${ }^{71}$ Such a catalyst was used to oxidize CO and unburned hydrocarbons in automotive emissions. The catalyst can retain its high activity for a long period, with minimal aggregation due to special structural architecture, where nano-particles are partially confined into the host compound. Such a concept was later further optimized to incorporate Rh, Pt and Pd into the catalytic converters by Daihatsu, and it is commonly called as "Super Intelligent Catalyst". ${ }^{71-73}$

Neagu and others further modified an ex-solution concept by selecting $\mathrm{SrTiO}_{3}$-type $\mathrm{MIEC}$ as the host compound, and
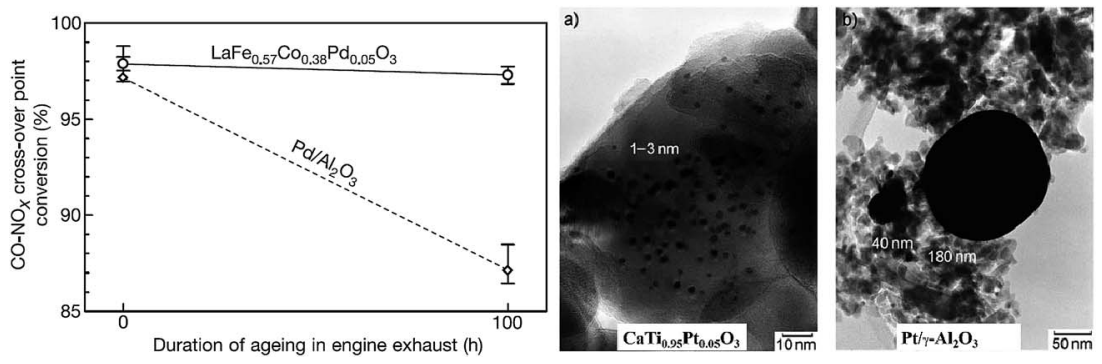

Fig. 9 The duration of ageing in engine exhausts of the perovskite-type $\mathrm{LaFe}_{0.57} \mathrm{Co}_{0.38} \mathrm{Pd}_{0.05} \mathrm{O}_{3}$ and conventional $\mathrm{Pd}-\mathrm{Al}_{2} \mathrm{O}_{3}$ composite for the conversion of $\mathrm{CO}$ and $\mathrm{NO}_{x}{ }^{71}$ TEM images of $\mathrm{Pt}$ grains of catalysts aged in engine exhausts at $900{ }^{\circ} \mathrm{C}$ for $100 \mathrm{~h}$ from $\mathrm{CaTi} \mathrm{O}_{0.95} \mathrm{Pt}_{0.05} \mathrm{O}_{3}$ and $\mathrm{Pt} / \gamma-\mathrm{Al}_{2} \mathrm{O}_{3}$ are shown for comparison. ${ }^{73}$ Reprinted with permission. 
replacing the precious metals with Ni for the HOR catalyst. ${ }^{74}$ For the first time, the new-type catalyst was demonstrated as a robust electrochemical catalyst for SOFCs and SOECs. ${ }^{68}$ The targeted dopants are first doped into the MIEC backbone in air, as they have high solubility to form a single-phase perovskitetype structure. As the MIEC is exposed at elevated temperatures under low $p_{\mathrm{O}_{2}}$, some dopants can be ex-soluted due to the change of the chemical solubility and formation of new chemical formulism of MIECs. The negative Gibbs free energy of the formation of net reaction drives this spontaneous chemical reduction reaction from their binary metal oxide systems at elevated temperatures under a reducing atmosphere. The Gibbs free energy of some common metal oxides as a function of temperature is shown in Fig. $10 .^{75}$ This diagram is generally used by metallurgists to find suitable temperature and $\mathrm{pO}_{2}$ for the reduction of the ores of important metals. For a given

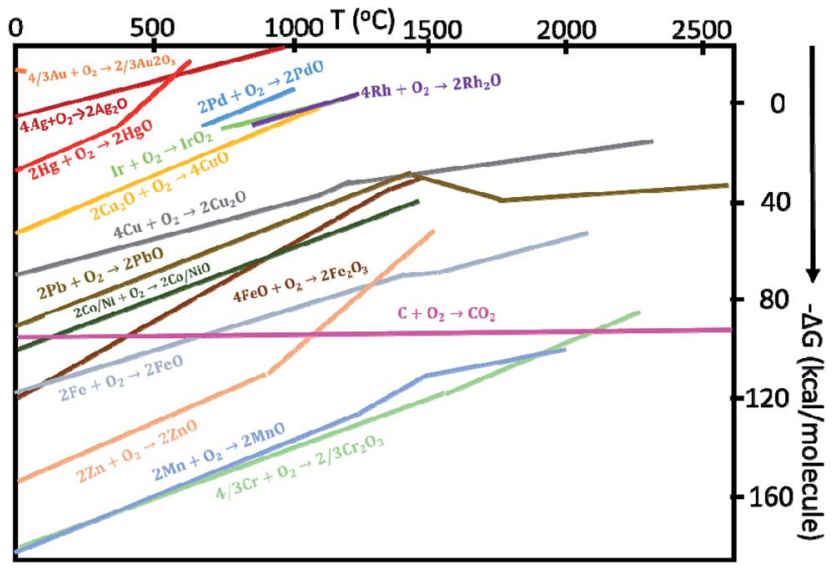

Fig. 10 The Gibbs free energy for some metal or metal oxide oxidation reactions as a function of temperature. ${ }^{75}$ reaction, the position of a line in the diagram shows the chemical/thermodynamic stability window of the metal oxides.

3.3.1 Ex-solution from A-site deficient perovskites. The general formula of a perovskite is $\mathrm{ABO}_{3}$ where $\mathrm{A}$ is a 12-coordination larger cation and $\mathrm{B}$ is a 6-coodination smaller cation. Various combinations of charges for A and B ions are feasible: $1+5,2+4$, and $3+3$. An ex-solution process can be initiated in the following scenarios in the perovskite-type structure: ${ }^{108}$

- For a stoichiometric perovskite $\mathrm{ABO}_{3}$, the ex-solution process can yield a B-site deficient perovskite $\mathrm{AB}_{1-x} \mathrm{O}_{3-\delta}$ and nanoparticles of B-site ions, i.e., $\mathrm{ABO}_{3(\mathrm{~s})} \rightarrow \mathrm{AB}_{1-x} \mathrm{O}_{3-\delta^{\prime}(\mathrm{s})}+x \mathrm{~B}_{(\mathrm{s})}$.

- For an A-site deficient perovskite $\mathrm{A}_{1-x} \mathrm{BO}_{3-\delta}$, the ex-solution process can yield a stoichiometric perovskite $\mathrm{ABO}_{3-\delta}$ and nanoparticles of $\mathrm{B}$-site ions, i.e., $\mathrm{A}_{1-x} \mathrm{BO}_{3-\delta(\mathrm{s})} \rightarrow(1-x)$ $\mathrm{ABO}_{3-\delta^{\prime}(\mathrm{s})}+x \mathrm{~B}_{(\mathrm{s})}$.

- For a stoichiometric perovskite $\mathrm{ABO}_{3}$, the ex-solution process can also yield $\mathrm{A}$ and $\mathrm{B}$-site defective perovskites $\mathrm{A}_{1-x} \mathrm{~B}_{1-y} \mathrm{O}_{3-\delta}$, nanoparticles of $\mathrm{A}$-site and $\mathrm{B}$-site ions, i.e., $\mathrm{ABO}_{3(\mathrm{~s})} \rightarrow \mathrm{A}_{1-x} \mathrm{~B}_{1-y} \mathrm{O}_{3-\delta^{\prime}(\mathrm{s})}+x \mathrm{~A}_{(\mathrm{s})}+y \mathrm{~B}_{(\mathrm{s})}$.

Early studies by Ruiz-Morales et al. suggested that defects could also be detrimental to the transport properties if their concentration exceeds a certain threshold, and defects tend to order in the structures as intergrowth structures, as shown in $\mathrm{La}_{4} \mathrm{Sr}_{n-4} \mathrm{Ti}_{n} \mathrm{O}_{3 n+2}$ (Fig. 11). ${ }^{109}$ By increasing the value of $n$ toward 12, the intergrowth layer diminished, and the oxide-ion conductivity reached its highest value. To characterize the microstructure of samples, Neagu et al. examined stoichiometric $\mathrm{La}_{0.3} \mathrm{Sr}_{0.7} \mathrm{Ti}_{0.94} \mathrm{M}_{0.06} \mathrm{O}_{3-\delta}(\mathrm{M}=\mathrm{Ti}, \mathrm{Ni})$, but they did not observe nanoparticle growth on the substrate. ${ }^{74}$ This result was not surprising since DFT calculations showed rather small negative Gibbs free energies for those transition metals. Furthermore, they investigated A-site deficient compounds, $\mathrm{La}_{0.4} \mathrm{Sr}_{0.4} \mathrm{Ti}_{0.94} \mathrm{M}_{0.06} \mathrm{O}_{3-\delta}(\mathrm{M}=\mathrm{Mn}$, Fe, Ni, and $\mathrm{Cu})$ and exsolution of nanoparticles was observed in high resolution
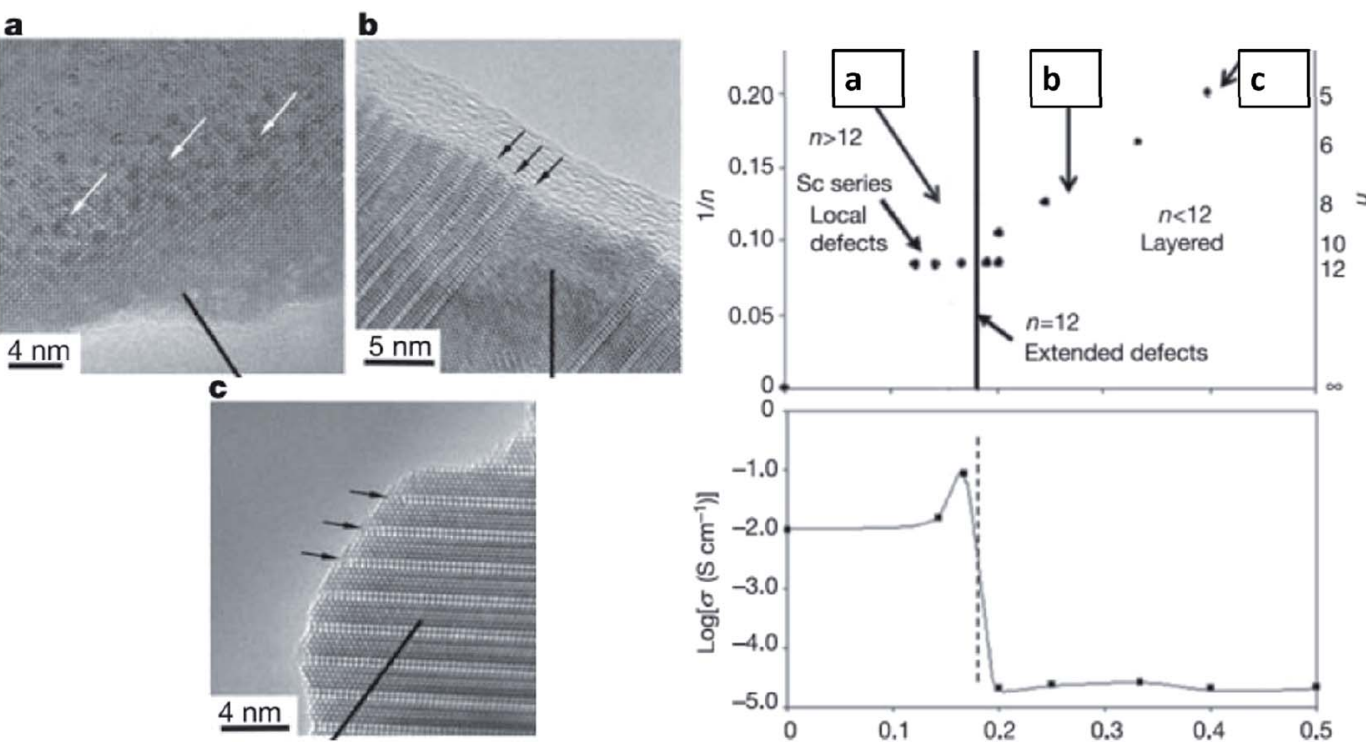

Fig. 11 The intergrowth of oxide-ion defects in the perovskite and their impact on the oxide-ion conductivity of $\mathrm{La}_{4} \mathrm{Sr}_{n-4} \mathrm{Ti}_{n} \mathrm{O}_{3 n+2 .}{ }^{109} \mathrm{Reprinted}$ with permission. 

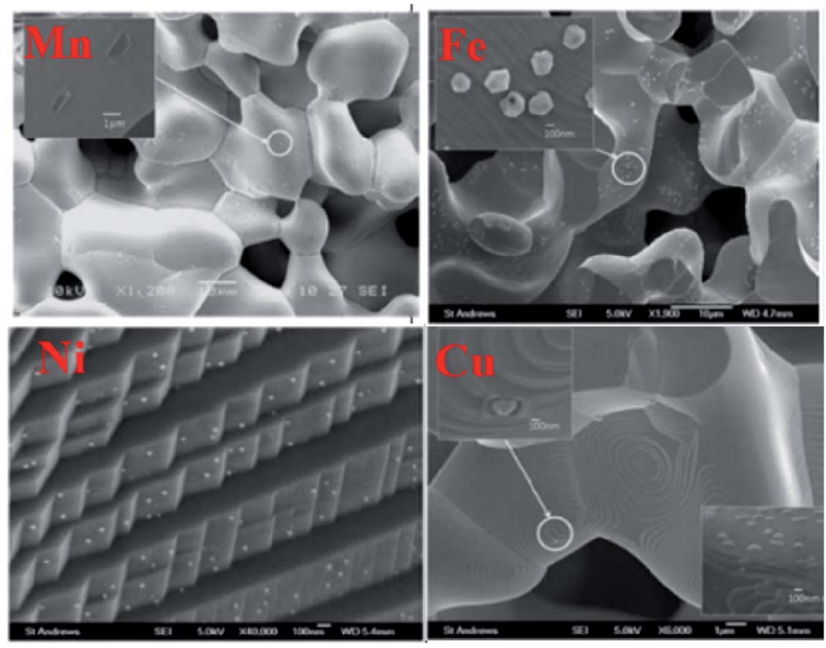

Fig. 12 Scanning electron microscopy (SEM) images of the ex-soluted nanoparticles from $\mathrm{La}_{0.4} \mathrm{Sr}_{0.4} \mathrm{Ti}_{0.94} \mathrm{M}_{0.06} \mathrm{O}_{3-\delta}(\mathrm{M}=\mathrm{Mn}, \mathrm{Fe}, \mathrm{Ni}$ and $\mathrm{Cu}){ }^{74}$ Reprinted with permission.

scanning electron microscopy images (Fig. 12). ${ }^{74}$ This result showed that off-stoichiometry could be a means to control the amount and size of nanoparticles ex-soluted on the host oxides. Neagu et al. pointed out that the case 2 is more feasible to exsolute metallic nanoparticles as the process involves "unstable" to "stable" conversion.

3.3.2 Surface-dependent ex-solution. Following Neagu et al. first publication on the ex-solution of A-site deficient perovskites, they have further studied about the micro-structure and elemental composition of host backbones. ${ }^{110}$ The native surface was found to be quite non-homogenous with A-site enriched composition; even the targeted perovskites were A-site deficient. As a result, only in the region where there is an A-site deficiency, were ex-solution nanoparticles formed. In contrast, nothing was growth in the separation between the terrace edges. Such a finding was consistent with the DFT calculation. They also tried to break the pellets into parts and analyzed the cleaved surfaces
(Fig. 13). It was interesting to see that the elemental ratio of such a surface was very similar to the targeted composition of the chemical formula of the perovskite. When this type of surface was exposed to a reducing atmosphere at elevated temperatures, the growth of homogenous nanoparticles was observed. ${ }^{102}$

In addition to the A-site deficient $\left(\mathrm{La}_{1-x} \mathrm{Sr}_{x}\right)_{1-y} \mathrm{TiO}_{3}$-type perovskites, ex-solution was also found in other structure-type hosts including fluorite-type $\mathrm{CeO}_{2}$, and rutile-type $\mathrm{NbTiO}_{4}$ (Fig. 14). ${ }^{111-115}$ Xiao and Qin found that $\mathrm{Sr}_{0.95} \mathrm{Ti}_{0.76} \mathrm{Nb}_{0.19} \mathrm{Ni}_{0.05} \mathrm{O}_{3}$ and $\mathrm{La}_{0.18} \mathrm{Sr}_{0.72^{-}}$ $\mathrm{Ti}_{0.9} \mathrm{Fe}_{0.1} \mathrm{O}_{3}$ perovksites could ex-solute nanoparticles of $\mathrm{Ni}$ and $\mathrm{Fe}$, respectively. ${ }^{111,12}$ Papargyriou and Yoon observed the ex-solution of $\mathrm{Ni}$ and Ru nanoparticles from $\mathrm{La}_{1-x} \mathrm{Sr}_{x} \mathrm{Cr}_{1-y} \mathrm{M}_{y} \mathrm{O}_{3}(\mathrm{M}=\mathrm{Mn}, \mathrm{Fe})$ and $\mathrm{La}_{0.4} \mathrm{Sr}_{0.6} \mathrm{Ti}_{1-x} \mathrm{Ru}_{x} \mathrm{O}_{3}(0<x<0.05)$, respectively. ${ }^{113,114}$ Thalinger et al. found, for the first time, that nanoparticles of $\mathrm{SrO}$ and $\mathrm{Fe}$ could be ex-soluted from the A and B-site stoichiometric perovskitetype $\mathrm{La}_{0.6} \mathrm{Sr}_{0.4} \mathrm{FeO}_{3} \cdot{ }^{115}$ These results have an important implication that $\mathrm{BaO}$ could be ex-soluted from the perovskite-type structure which showed anti-coking properties by facilitating the $\mathrm{H}_{2} \mathrm{O}$ vapor to oxidize deposited carbon. ${ }^{116}$

For the first time, Qi and Wei reported metal/metal alloy exsolution in a non-perovskite-type structure. For example, $\mathrm{Ni}$ and $\mathrm{Ni}_{1-x} \mathrm{Cu}_{x}$ were stabilized from $\mathrm{Ce}_{0.9} \mathrm{Ni}_{0.1} \mathrm{O}_{2}$ and $\mathrm{NbTi}_{0.5} \mathrm{Ni}_{0.25^{-}}$ $\mathrm{Cu}_{0.25} \mathrm{O}_{4}$, respectively (Fig. 15). ${ }^{117,118}$ The latter alloy is of great interest as the catalytic activity and chemical stability could be tailored as a function of $\mathrm{Cu}$ content. Nonetheless, the strategic design poses some difficulties in the control of well-defined alloys and their microstructures. Using TGA, Sun et al. showed that the onset temperatures for the reduction reaction of $\mathrm{Ni}$ and Fe are slightly different (Fig. 16) ${ }^{66}$ As a result, a core-shell structure for some of the ex-soluted species could be observed with a Fe-rich core and Ni-rich shell. Nonetheless, it is very challenging to understand the reduction behavior of individual species (e.g., Ni and Fe) from TGA and PXRD. These observations provided the valuable information about the total reduction of $\mathrm{Ni}$ and $\mathrm{Fe}$. Stoichiometry and defects could alter the lattice energy of metal oxide systems, and affect both the kinetics and the thermodynamics of the ex-solution processes. ${ }^{119-121}$

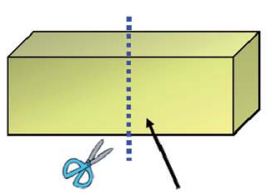

Native surface

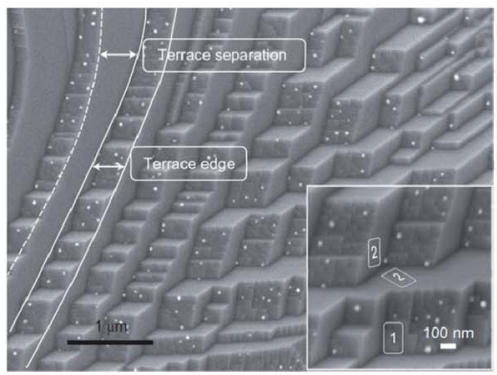

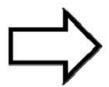
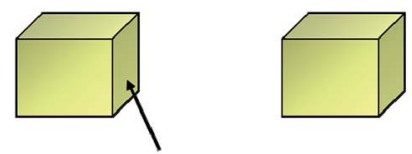

Cleaved surface

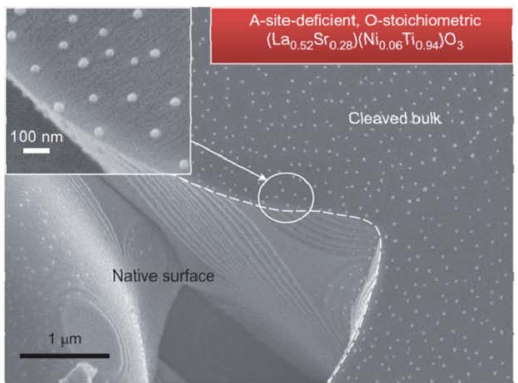

Fig. 13 Schematic diagram of the surface-dependent ex-solution for $\mathrm{La}_{0.52} \mathrm{Sr}_{0.28} \mathrm{Ni}_{0.06} \mathrm{Ti}_{0.94} \mathrm{O}_{3} \cdot{ }^{110}$ Reprinted with permission. 


\section{A-site Deficient Perovskites}
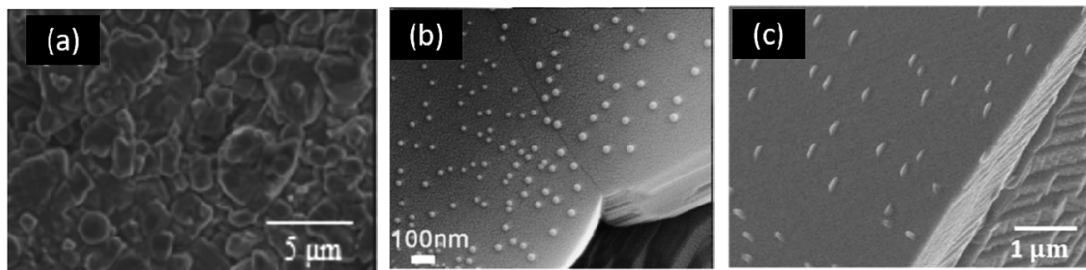

\section{Stoichiometric Perovskites}
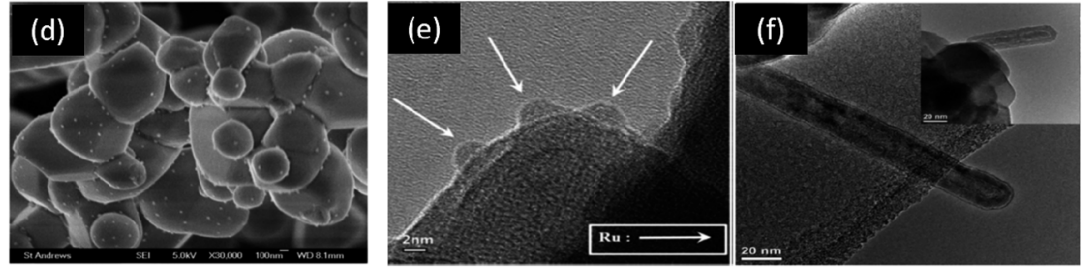

Fig. 14 Typical example of A-site deficient and stoichiometric perovskites that ex-solute nanoparticles in reducing atmospheres at elevated temperatures. ${ }^{111-115}$ (a) $\mathrm{La}_{0.18} \mathrm{Sr}_{0.72} \mathrm{Ti}_{0.9} \mathrm{Fe}_{0.1} \mathrm{O}_{3,}{ }^{112}$ (b) $\mathrm{Sr}_{0.95} \mathrm{Ti}_{0.76} \mathrm{Nb}_{0.19} \mathrm{Ni}_{0.05} \mathrm{O}_{3,}{ }^{111}$ (c) $\mathrm{La}_{0.4} \mathrm{Sr}_{0.4} \mathrm{Ti}_{0.94} \mathrm{Ni}_{0.06} \mathrm{O}_{3},{ }^{112}$ (d) $\mathrm{La}_{0.75} \mathrm{Sr}_{0.25} \mathrm{Cr}_{0.475} \mathrm{Fe}_{0.475} \mathrm{Ni}_{0.05} \mathrm{O}_{3}{ }^{113}$ (e) $\mathrm{La}_{0.4} \mathrm{Sr}_{0.6} \mathrm{Ti}_{1-x} \mathrm{Ru}_{x} \mathrm{O}_{3}{ }^{114}$ and (f) $\mathrm{La}_{0.6} \mathrm{Sr}_{0.4} \mathrm{FeO}_{3}{ }^{115}$ Reprinted with permission.

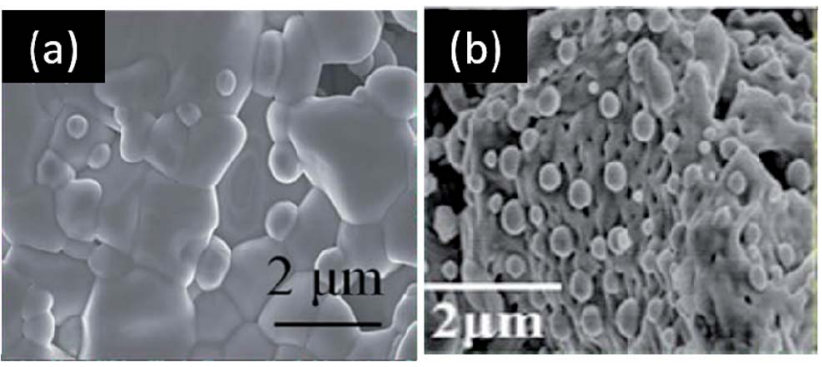

Fig. 15 Scanning electron microscopy (SEM) images of $\mathrm{Ni}$ and $\mathrm{Ni}_{1-x^{-}}$ $\mathrm{Cu}_{x}$ nanoparticles ex-soluted from $\mathrm{Ce}_{0.9} \mathrm{Ni}_{0.1} \mathrm{O}_{2}$ (a) and $\mathrm{NbTi}_{0.5}$ $\mathrm{Ni}_{0.25} \mathrm{Cu}_{0.25} \mathrm{O}_{4}$ (b), respectively. ${ }_{1}^{117,118}$ Reprinted with permission.

Besides SEM images, Neagu et al. studied the microstructure of the substrate after treatment with acid to dissolve the $\mathrm{Ni}$ nanoparticles grown on its surface. ${ }^{\mathbf{1 1 0}}$ Atomic-force microscopy
(AFM) images revealed that the part of the ex-soluted nanoparticles were embedded in the substrate at about $100 \mathrm{~nm}$ deep (Fig. 17). ${ }^{110}$ Such nano-socked Ni particles were later found to have better thermal and chemical stability over sintering and coking, respectively. They hypothesized that the diffusion of $\mathrm{Ni}$ particles could be hard since they have to overcome the large barrier of the socket where they are located. Moreover, the carbon nanotubes are highly limited to grow to certain directions, and therefore, the Ni-locked surface seems to have less coking compared to bare Ni surfaces.

Very recently, Oh et al. further studied the formation mechanism of these ex-soluted nanoparticles by using AFM on surfaces to understand different exposure times in reducing atmospheres (Fig. 18). ${ }^{\mathbf{1 2 2}}$ They observed that some pits were formed prior to the emergence of nanoparticles. They hypothesized that a movement of ions should occur near the surface to form pits at $600{ }^{\circ} \mathrm{C}$ in dry $\mathrm{H}_{2}$. At $700{ }^{\circ} \mathrm{C}$, Ni nanoparticles were
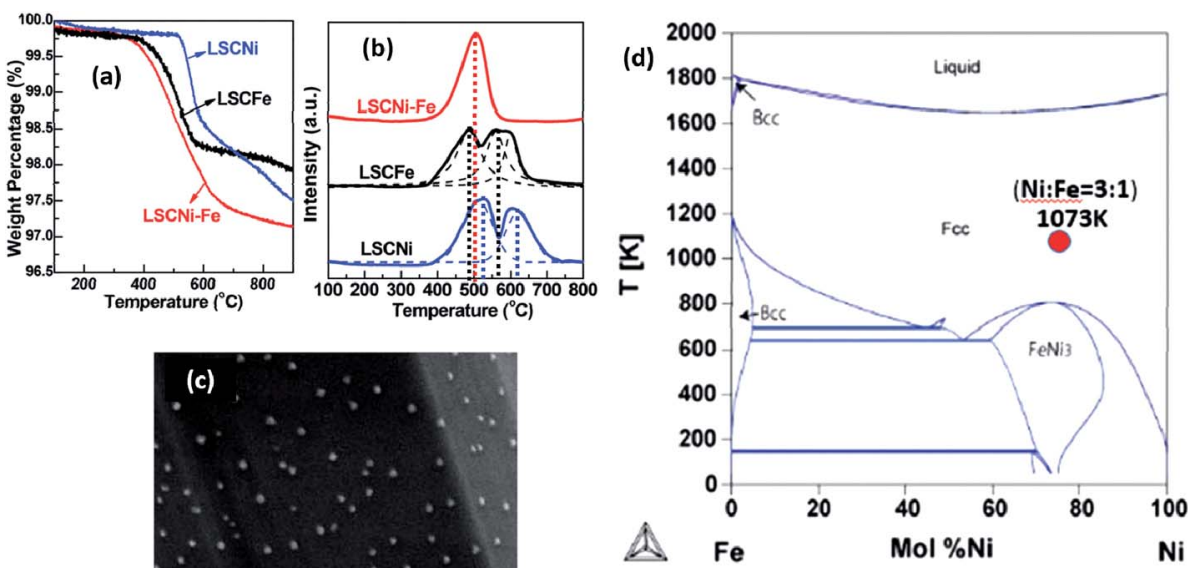

Fig. 16 (a) Thermogravimetric analysis (TGA), (b) temperature programmed reduction (TPR) and (c) scanning electron microscopy (SEM) of the

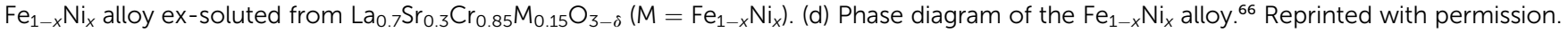


(a)

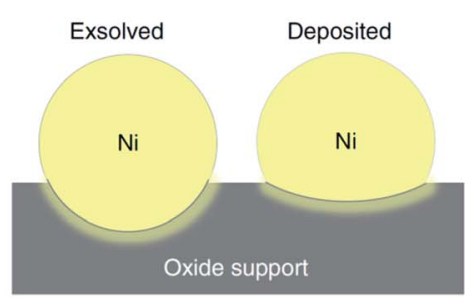

(d)

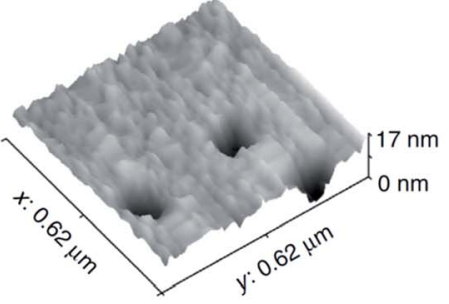

(b)

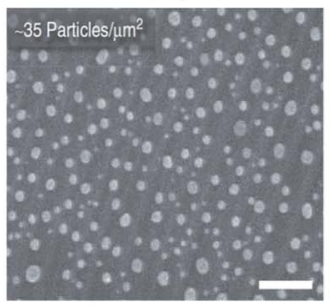

(e)

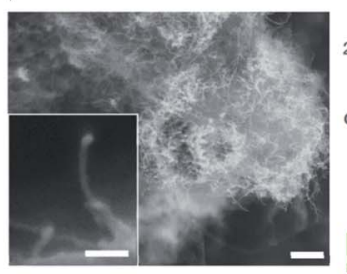

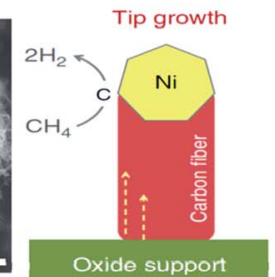

(c)

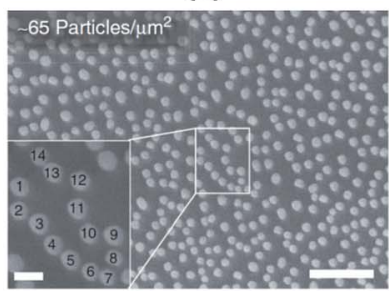

(f)

Fig. 17 (a) Schematic illustration of the particle-substrate interface for deposited and ex-soluted Ni particles on the oxide backbone, (b) and (c) SEM micrographs of vapour-deposited Ni particles on the perovskite-type $\mathrm{La}_{0.4} \mathrm{Sr}_{0.4} \mathrm{TiO}_{3}$ surface, (d) three-dimensional AFM images showing sockets of $\mathrm{Ni}$ after etching in $\mathrm{HNO}_{3}$, and (e) and (f) SEM micrographs of Ni-deposited $\mathrm{La}_{0.4} \mathrm{Sr}_{0.4} \mathrm{TiO}_{3}$ samples after the coking test and schematic of possible carbon fiber growth mechanisms. ${ }^{110}$ Reprinted with permission.

found to grow confined inside the pits. Such an observation might indicate that the species involved in the ionic diffusion in the first stage are likely different from the species that emerged in the second stage.

Previous studies have shown that bond valence sum (BVS) has been used to predict the ionic pathways in solids..$^{35,123-127}$ Kan et al. recently explored the use of a BVS map to predict the diffusion behavior of ions in the perovskite-type structure at elevated temperatures. ${ }^{124}$ The ex-solution mechanism is yet to be understood deeply; however, it is likely involved in the diffusion of cations to the surface before the cations are being reduced. BVS calculations could be useful to understand bond valence of metals before and after ex-solution and to understand structural stability. The low BVS mismatch pathways may suggest the facile diffusion pathways for particular ions. Calculation was conducted on various Ni-doped perovskite-type $\mathrm{SrTiO}_{3}$ compounds to understand the potential ex-solution of A and/or B-site ions. The results revealed an interesting phenomenon that $\mathrm{Sr}^{2+}$ ions in the A-site (with smaller BVS mismatches) are more ready to diffuse than the $\mathrm{Ni}^{2+}$ ions in the B-site (Fig. 19), suggesting that the formation of the metal might be initiated by the migration of A-site ions.

Conventional Ni-based SOFC anodes are known to suffer coking and poisoning when hydrocarbons with $\mathrm{ppm} \mathrm{H}_{2} \mathrm{~S}$ are used as fuels. On the other hand, many MIECs are shown to have higher chemical stability toward those fuels, but less
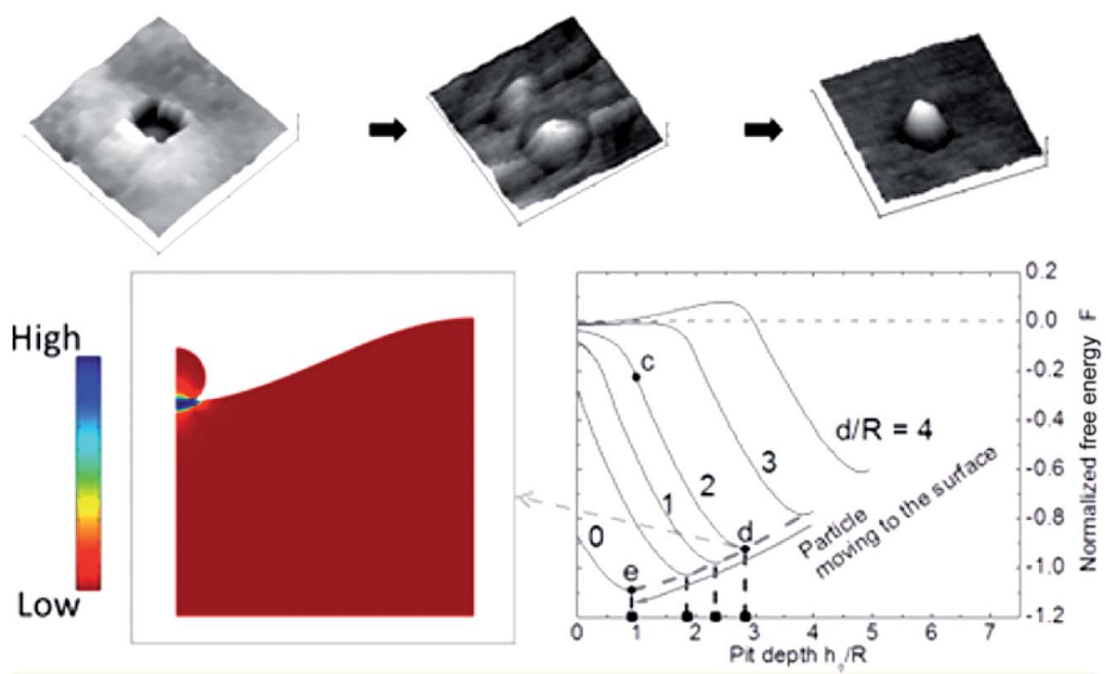

Fig. 18 Top panel shows the AFM images of pit in the perovskite-type $\mathrm{La}_{0.4} \mathrm{Sr}_{0.4} \mathrm{Ti}_{0.97} \mathrm{Ni}_{0.03} \mathrm{O}_{3-\delta}$ after reduction at $600{ }^{\circ} \mathrm{C}$ under dry $\mathrm{H}_{2}$ and $700{ }^{\circ} \mathrm{C}$ under dry $\mathrm{H}_{2}$, and the bottom panel shows the calculated normalized free energy versus pit depth. ${ }^{122}$ Reprinted with permission. 

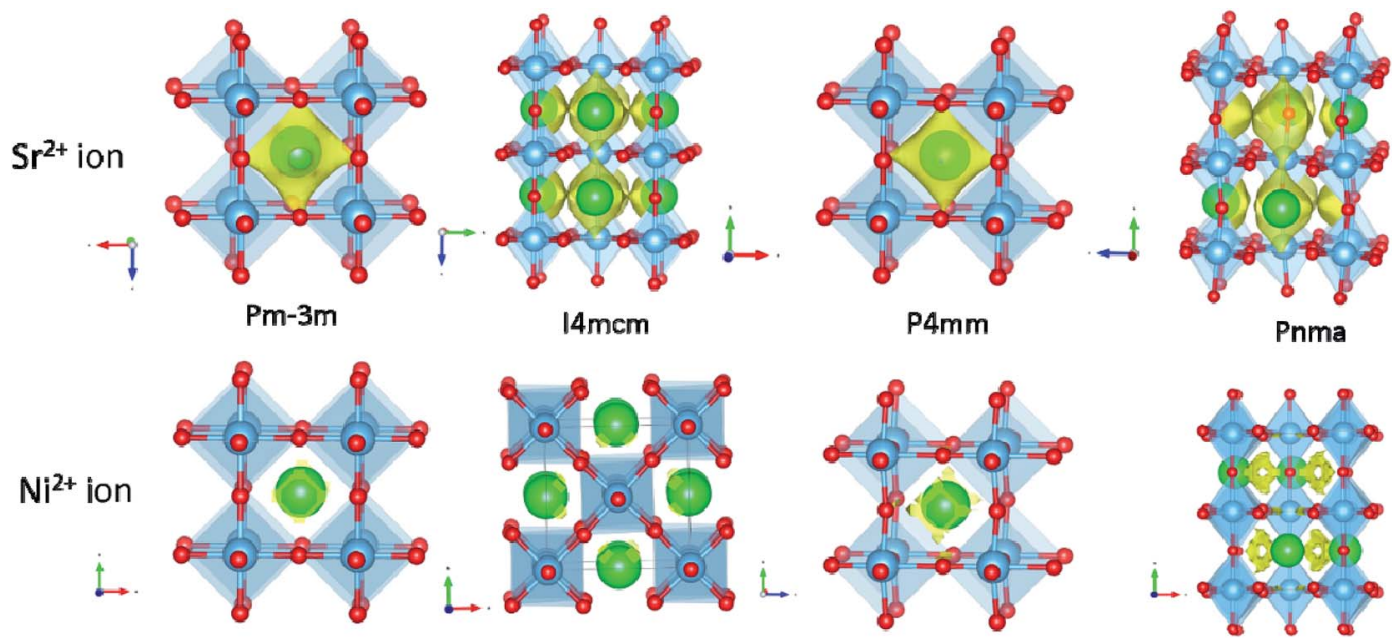

Fig. 19 Bond valance sum (BVS) map calculation revealed the $\mathrm{Sr}^{2+}$ and $\mathrm{Ni}^{2+}$ ions conduction pathway in the perovskite-type $\mathrm{SrTiO}_{3}$ compound. 3D BVSMAPPER was used to calculate the BVS map. ${ }^{127}$ The yellow contour surface with a low BVS mismatch of 10 and 2 for $\mathrm{Sr}^{2+}$ and $\mathrm{Ni}^{2+}$ ions in $\mathrm{SrTi}_{0.95} \mathrm{Ni}_{0.5} \mathrm{O}_{3}$ with different space groups. The imported crystallographic information files (cif) were obtained from the International Centre for Diffraction Data (ICDD) database (J. Phys. Soc. Jpn., 1965, 20, 179; J. Phys. Soc. Jpn., 1978, 45, 206; Mater. Res. Bull., 1973, 8. 545; Philos. Mag., 2006, 86, 2283).

electrochemically active resulting in lower power outputs. Among the reported MIECs, $\mathrm{La}_{1-x} \mathrm{Sr}_{x} \mathrm{TiO}_{3}$ (LST) is known to be highly stable in hydrocarbons and $\mathrm{H}_{2} \mathrm{~S}$, but it also has a drawback of low electrochemical activity. Sun et al. tried to improve the electrochemical activity of LST-type perovskites by decorating their surface with nano-sized $\mathrm{Ni}$ and Ce through an exsolution method. ${ }^{128} \mathrm{~A}$ series of $\mathrm{Ni}$ and Ce-doped $\mathrm{La}_{0.3} \mathrm{Sr}_{0.6^{-}}$ $\mathrm{Ce}_{0.1} \mathrm{Ni}_{0.1} \mathrm{Ti}_{0.9} \mathrm{O}_{3}$ perovskites were prepared and their HOR activity was investigated (Table 1) ${ }^{66}$ On the basis of their $I-V$ curves, the Ni and Ce co-doped samples (LSCNT) reached an impressive peak power density of $650 \mathrm{~mW} \mathrm{~cm}^{-2}$ in $5000 \mathrm{ppm}$ $\mathrm{H}_{2} \mathrm{~S} / \mathrm{H}_{2}$ at $900{ }^{\circ} \mathrm{C}$, and it may be related to the small polarization resistance of $0.2 \Omega \mathrm{cm}^{2}$. Similarly, the LSCNT also showed a reasonably high peak power density of $600 \mathrm{~mW} \mathrm{~cm}{ }^{-2}$ in dry $\mathrm{CH}_{4}$. Several perovskite-type compounds such as $\mathrm{La}_{0.7} \mathrm{Sr}_{0.3^{-}}$ $\mathrm{Cr}_{0.85} \mathrm{Ni}_{0.15} \mathrm{O}_{3}$ (LSCNi), $\mathrm{La}_{0.7} \mathrm{Sr}_{0.3} \mathrm{Cr}_{0.85} \mathrm{Fe}_{0.15} \mathrm{O}_{3}$ (LSCFe), and $\mathrm{La}_{0.7} \mathrm{Sr}_{0.3} \mathrm{Cr}_{0.85} \mathrm{Ni}_{0.11} \mathrm{Fe}_{0.04} \mathrm{O}_{3}$ (LSCNi-Fe) were also studied in $5000 \mathrm{ppm} \mathrm{H}_{2} \mathrm{~S} / \mathrm{H}_{2}$ at $800{ }^{\circ} \mathrm{C} .{ }^{66}$
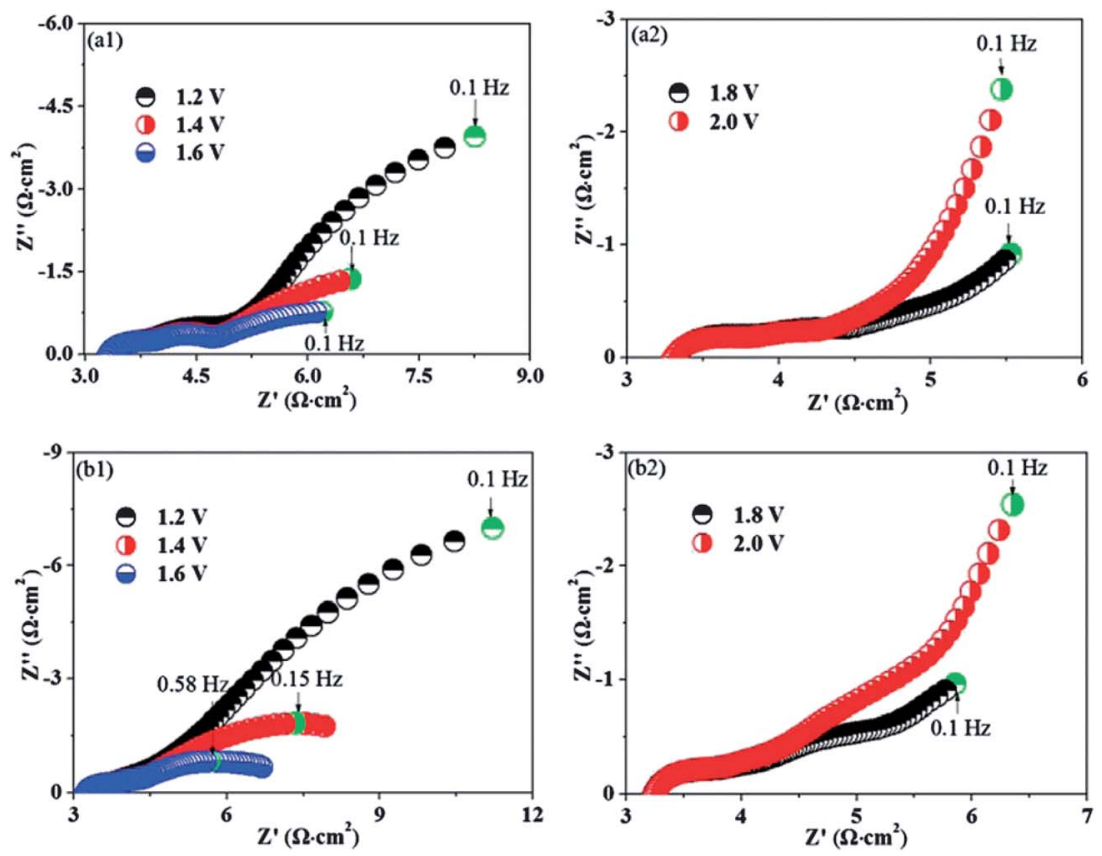

Fig. 20 The electrochemical ac impedance spectra of $\mathrm{La}_{0.3} \mathrm{Sr}_{0.7} \mathrm{TiO}_{3}(\mathrm{LST})$ and $\left(\mathrm{La}_{0.3} \mathrm{Sr}_{0.7}\right)_{0.9} \mathrm{Ti}_{0.9} \mathrm{Ni}_{0.1} \mathrm{O}_{3-\delta}(\mathrm{LSTN})$ in a mixture of $3 \% \mathrm{H}{ }_{2} \mathrm{O}, 5 \% \mathrm{H}{ }_{2}$ and $93 \% \mathrm{Ar}$ at $800{ }^{\circ} \mathrm{C}$ (left). ${ }^{129}$ Reprinted with permission. 
Besides SOFC application, the perovskites were also studied as electrodes for SOECs to convert steam into $\mathrm{H}_{2}$ and $\mathrm{O}_{2}$. Zhang et al. investigated $\mathrm{Ni}$ nanoparticles embedded in host $\mathrm{La}_{0.3} \mathrm{Sr}_{0.7} \mathrm{TiO}_{3}$ and they demonstrated a significant enhancement by $20-30 \%$ of current efficiency in their steam electrolysis, compared to the bare $\mathrm{La}_{0.3} \mathrm{Sr}_{0.7} \mathrm{TiO}_{3}$ (LST) (Fig. 20). ${ }^{129}$ The improvement was due to the lower polarization resistance of the LSTN sample compared to LST. ${ }^{129}$ The Ni nanoparticles seem to be re-dissolved into the host perovskite upon switching to an oxidizing atmosphere. The powder X-ray diffraction patterns showed that the crystal structure was maintained after two redox cycles at $1300{ }^{\circ} \mathrm{C}$ for $10 \mathrm{~h}$, while no nanoparticles and crack were observed in the SEM images. Both suggested that $\mathrm{Ni}$ re-dissolution was fairly completed.

\section{Future prospects}

Various synthetic methods to prepare the nano-structural electrodes for SOFCs were briefly reviewed in this study. Some of them did show improved performance of electrodes under various fuel conditions; however, most literature studies did not report long-term operating performances, suggesting that the durability test is required before commercializing these promising nano-structured electrodes in SOFCs. Moreover, the scale up process remains an open area for further work. Amongst the reported nano-structural approaches, the ex-solution-type method has showed some promise to mitigate the unwanted side reactions, such as the suppression of the growth of carbon in hydrocarbon fuels. However, ex-solution is strongly limited by the solubility of dopants in the host structure and their density on surfaces seems to be hard to control at the large scale production, unlike conventional composite electrodes. A few reports claim to report the synthesis of bimetallic particles by the ex-solution method, but ambiguity was raised due to the fact that the diffusion coefficient of various ions was not considered. So far, there seems to be no systematic study to quantify the amount of dopants being ex-soluted as a function of temperature. Using in situ synchrotron X-ray and neutron diffraction measurements, due to their strong penetration depth and their sensitivity, one could fill this gap. With the use of certain constrain conditions in the Rietveld refinement, a quantitative analysis of the ex-soluted particles as a function of temperature and atmosphere could be estimated. Also, the ex-solution-type cathode for SOFCs is a rather unexplored area of research. In summary, the fundamental understanding of the microstructure-property relationships of electrodes is critical for the development of next generation electrodes for SOFCs. With similar materials and preparation techniques, it is entirely possible that such a methodology may also be transferable to electrolysis SOECs application.

\section{Abbreviations}

$\begin{array}{ll}E_{\mathrm{A}, \mathrm{D}} * & \begin{array}{l}\text { activation energy for oxygen tracer diffusion } / \mathrm{kJ} \\ \mathrm{mol}^{-1}\end{array} \\ \Delta G & \begin{array}{l}\text { Gibbs free energy/kcal molecule } \\ \text { partial pressure of oxygen/atm }\end{array} \\ p \mathrm{O}_{2} & \text { par }\end{array}$

\begin{tabular}{|c|c|}
\hline$P_{\max }$ & peak power density/W $\mathrm{cm}^{-2}$ \\
\hline$R_{\mathrm{p}}$ & polarization resistance $/ \Omega \mathrm{cm}^{2}$ \\
\hline$\sigma$ & oxide ion conductivity/S $\mathrm{cm}^{-1}$ \\
\hline$T$ & temperature $/{ }^{\circ} \mathrm{C}$ or $\mathrm{K}$ \\
\hline$V_{\mathrm{O}}^{\ddot{*}}$ & oxygen vacancy \\
\hline$Z^{\prime}$ & real part of impedance $/ \Omega \mathrm{cm}^{2}$ \\
\hline$Z^{\prime \prime}$ & imaginary part of impedance $/ \Omega \mathrm{cm}^{2}$ \\
\hline AFM & atomic force microscopy \\
\hline ASR & area specific polarization resistance \\
\hline BICUVOX & $\mathrm{Bi}_{2} \mathrm{~V}_{0.9} \mathrm{Cu}_{0.1} \mathrm{O}_{5.35}$ \\
\hline BSCF & $\mathrm{Ba}_{1-x} \mathrm{Sr}_{x} \mathrm{Co}_{1-y} \mathrm{Fe}_{y} \mathrm{O}_{3-\delta}$ \\
\hline BVS & bond valence sum \\
\hline CGO & Gd-doped $\mathrm{CeO}_{2}$ \\
\hline CVD & chemical vapor deposition \\
\hline DFT & density functional theory \\
\hline EIS & electrochemical impedance spectroscopy \\
\hline EPD & electrophoretic deposition \\
\hline HOR & hydrogen oxidation reaction \\
\hline LSC & $\mathrm{La}_{1-x} \mathrm{Sr}_{x} \mathrm{CoO}_{3-\delta}$ \\
\hline LSC-113 & $\mathrm{La}_{0.6} \mathrm{Sr}_{0.4} \mathrm{CoO}_{3-\delta}$ \\
\hline LSC-214 & $(\mathrm{La}, \mathrm{Sr})_{2} \mathrm{CoO}_{4}$ \\
\hline LSCF & $\mathrm{La}_{1-x} \mathrm{Sr}_{x} \mathrm{Co}_{1-y} \mathrm{Fe}_{y} \mathrm{O}_{3-\delta}$ \\
\hline LSCFe & $\mathrm{La}_{0.7} \mathrm{Sr}_{0.3} \mathrm{Cr}_{0.85} \mathrm{Fe}_{0.15} \mathrm{O}_{3}$ \\
\hline LSCNi & $\mathrm{La}_{0.7} \mathrm{Sr}_{0.3} \mathrm{Cr}_{0.85} \mathrm{Ni}_{0.15} \mathrm{O}_{3}$ \\
\hline LSCNi-Fe & $\mathrm{La}_{0.7} \mathrm{Sr}_{0.3} \mathrm{Cr}_{0.85} \mathrm{Ni}_{0.11} \mathrm{Fe}_{0.04} \mathrm{O}_{3}$ \\
\hline LSCNT & $\mathrm{La}_{0.3} \mathrm{Sr}_{0.6} \mathrm{Ce}_{0.1} \mathrm{Ni}_{0.1} \mathrm{Ti}_{0.9} \mathrm{O}_{3}$ \\
\hline LSGM & $\mathrm{Sr}$ and $\mathrm{Mg}$-co-doped $\mathrm{LaGaO}_{3}$ \\
\hline LSM & $\mathrm{La}_{1-x} \mathrm{Sr}_{x} \mathrm{MnO}_{3}$ \\
\hline LST & $\mathrm{La}_{1-x} \mathrm{Sr}_{x} \mathrm{TiO}_{3}$ \\
\hline LSTN & $\left(\mathrm{La}_{0.3} \mathrm{Sr}_{0.7}\right)_{0.9} \mathrm{Ti}_{0.9} \mathrm{Ni}_{0.1} \mathrm{O}_{3-\delta}$ \\
\hline MIEC & mixed ionic and electronic conductor \\
\hline OCV & open circuit voltage \\
\hline ORR & oxygen reduction reaction \\
\hline PLD & pulsed laser deposition \\
\hline PVD & physical vapor deposition \\
\hline PXRD & powder X-ray diffraction \\
\hline SC & $\mathrm{SrCoO}_{3-\delta}$ \\
\hline SSC & $\mathrm{Sm}_{0.5} \mathrm{Sr}_{0.5} \mathrm{CoO}_{3}$ \\
\hline SDC & Sm-doped $\mathrm{CeO}_{2}$ \\
\hline SEM & scanning electron microscopy \\
\hline SOEC & solid oxide electrolysis cell \\
\hline SOFC & solid oxide fuel cell \\
\hline TEC & thermal expansion coefficient \\
\hline TEM & transmission electron microscopy \\
\hline TGA & thermogravimetric analysis \\
\hline ТPB & triple phase boundary \\
\hline TPR & temperature programmed reduction \\
\hline XPS & X-ray photoelectron spectroscopy \\
\hline YSZ & Y-doped $\mathrm{ZrO}_{2}$ \\
\hline
\end{tabular}

\section{Acknowledgements}

V. T. acknowledges the support from the Natural Sciences and Engineering Research Council of Canada thorough the Discovery Grants program (Grant Number: RGPIN-2016-03853). W. H. K. acknowledges the financial support from the China Spallation Neutron Source, the institute of High Energy Physics, Chinese Academy of Sciences. 


\section{References}

1 A. D. Boyd, Int. J. Greenhouse Gas Control, 2015, 32, 81-89.

2 J. Twidell and T. Weir, Renewable Energy Resources, Taylor \& Francis, 2015.

3 A. Atkinson, S. Barnett, R. J. Gorte, J. T. S. Irvine, A. J. McEvoy, M. Mogensen, S. C. Singhal and J. Vohs, Nat. Mater., 2004, 3, 17-27.

4 R. O'Hayre, S. W. Cha, W. Colella and F. B. Prinz, Fuel Cell Fundamentals, Wiley, 2009.

5 K. Huang and J. B. Goodenough, Solid Oxide Fuel Cell Technology: Principles, Performance and Operations, Elsevier Science, 2009.

$6 \mathrm{~J} . \quad$ T. S. Irvine, D. Neagu, M. C. Verbraeken, C. Chatzichristodoulou, C. Graves and M. B. Mogensen, Nat. Energy, 2016, 1, 15014.

7 W. H. Kan and V. Thangadurai, Ionics, 2015, 21, 301-318.

8 E. D. Wachsman and K. T. Lee, Science, 2011, 334, 935-939.

9 N. Behling, Fuel Cells Current Technology Challenges and Future Research Needs, Elsevier, 1st edn, 2012.

10 S. P. Jiang, Int. J. Hydrogen Energy, 2012, 37, 449-470.

11 Z. Liu, B. Liu, D. Ding, M. Liu, F. Chen and C. Xia, J. Power Sources, 2013, 237, 243-259.

12 T. Sholklapper, C. Jacobson, S. Visco and L. De Jonghe, Fuel Cells, 2008, 8, 303-312.

13 E. Perry Murray and S. A. Barnett, Solid State Ionics, 2001, 143, 265-273.

14 T. Kenjo and M. Nishiya, Solid State Ionics, 1992, 57, 295302.

15 M. J. Jørgensen, S. Primdahl, C. Bagger and M. Mogensen, Solid State Ionics, 2001, 139, 1-11.

16 M. J. L. Østergård, C. Clausen, C. Bagger and M. Mogensen, Electrochim. Acta, 1995, 40, 1971-1981.

17 E. V. Tsipis and V. V. Kharton, J. Solid State Electrochem., 2008, 12, 1367-1391.

18 Z. Shao and S. M. Haile, Nature, 2004, 431, 170-173.

19 J.-H. Kim and A. Manthiram, J. Mater. Chem. A, 2015, 3, 24195-24210.

20 S. P. Jiang, Solid State Ionics, 2002, 146, 1-22.

21 A. Esquirol, N. P. Brandon, J. A. Kilner and M. Mogensen, J. Electrochem. Soc., 2004, 151, A1847-A1855.

22 A. V. Berenov, A. Atkinson, J. A. Kilner, E. Bucher and W. Sitte, Solid State Ionics, 2010, 181, 819-826.

23 P. S. Manning, J. D. Sirman and J. A. Kilner, Solid State Ionics, 1996, 93, 125-132.

24 T. Ishihara, H. Matsuda and Y. Takita, J. Am. Chem. Soc., 1994, 116, 3801-3803.

25 F. Abraham, J. C. Boivin, G. Mairesse and G. Nowogrocki, Solid State Ionics, 1990, 40-41, 934-937.

26 J. W. Stevenson, T. R. Armstrong, L. R. Pederson, J. Li, C. A. Lewinsohn and S. Baskaran, Solid State Ionics, 1998, 113-115, 571-583.

27 E. Djurado and M. Labeau, J. Eur. Ceram. Soc., 1998, 18, 1397-1404.

28 S. H. Chan, X. J. Chen and K. A. Khor, Solid State Ionics, 2003, 158, 29-43.
29 Y. J. Leng and S. H. Chan, Electrochem. Solid-State Lett., 2006, 9, A56-A59.

30 E. D. Wachsman, P. Jayaweera, N. Jiang, D. M. Lowe and B. G. Pound, J. Electrochem. Soc., 1997, 144, 233-236.

31 J. S. Ahn, D. Pergolesi, M. A. Camaratta, H. Yoon, B. W. Lee, K. T. Lee, D. W. Jung, E. Traversa and E. D. Wachsman, Electrochem. Commun., 2009, 11, 1504-1507.

32 J. C. Boivin and G. Mairesse, Chem. Mater., 1998, 10, 28702888.

33 A. Orera and P. R. Slater, Chem. Mater., 2010, 22, 675-690.

34 P. Singh and J. B. Goodenough, Energy Environ. Sci., 2012, 5, 9626-9631.

35 W. H. Kan, K.-Y. Lai, A. Huq and A. Manthiram, J. Power Sources, 2016, 307, 454-461.

36 C. Xia and M. Liu, Adv. Mater., 2002, 14, 521-523.

37 H. S. Spacil, US Pat., US3503809 A, 1970.

38 R. J. Gorte and J. M. Vohs, Curr. Opin. Colloid Interface Sci., 2009, 14, 236-244.

39 S. Zha, Z. Cheng and M. Liu, J. Electrochem. Soc., 2007, 154, B201-B206.

40 C. Zhang, M. E. Grass, A. H. McDaniel, S. C. DeCaluwe, F. E. Gabaly, Z. Liu, K. F. McCarty, R. L. Farrow, M. A. Linne, Z. Hussain, G. S. Jackson, H. Bluhm and B. W. Eichhorn, Nat. Mater., 2010, 9, 944-949.

41 W. C. Chueh, Y. Hao, W. Jung and S. M. Haile, Nat. Mater., 2011, 11, 155-161.

42 M. Chen, S. Paulson, W. H. Kan, V. Thangadurai and V. Birss, J. Mater. Chem. A, 2015, 3, 22614-22626.

43 L. Deleebeeck and V. Birss, Solid State Ionics, 2011, 203, 6979.

44 Z. Gao, L. V. Mogni, E. C. Miller, J. G. Railsback and S. A. Barnett, Energy Environ. Sci., 2016, 9, 1602-1644.

45 N. M. Sammes, Y. Du and R. Bove, J. Power Sources, 2005, 145, 428-434.

46 T. Suzuki, T. Yamaguchi, Y. Fujishiro and M. Awano, J. Power Sources, 2006, 160, 73-77.

47 Y. Funahashi, T. Shimamori, T. Suzuki, Y. Fujishiro and M. Awano, J. Power Sources, 2007, 163, 731-736.

48 A. Evans, A. Bieberle-Huetter, J. L. M. Rupp and L. J. Gauckler, J. Power Sources, 2009, 194, 119-129.

49 C.-W. Kwon, J.-W. Son, J.-H. Lee, H.-M. Kim, H.-W. Lee and K.-B. Kim, Adv. Funct. Mater., 2011, 21, 1154-1159.

50 S. C. Singhal and K. Kendall, High-temperature Solid Oxide Fuel Cells: Fundamentals, Design and Applications, Elsevier Science, 2003.

51 F. M. Figueiredo, J. A. Labrincha, J. R. Frade and F. M. B. Marques, Solid State Ionics, 1997, 101-103, 343-349.

52 H. Yokokawa, N. Sakai, T. Kawada and M. Dokiya, J. Electrochem. Soc., 1991, 138, 2719-2727.

53 J. M. Vohs and R. J. Gorte, Adv. Mater., 2009, 21, 943-956.

54 A. Samson, M. Søgaard, R. Knibbe and N. Bonanos, J. Electrochem. Soc., 2011, 158, B650-B659.

55 A. Evans, A. Bieberle-Hütter, J. L. M. Rupp and L. J. Gauckler, J. Power Sources, 2009, 194, 119-129.

56 D. Beckel, A. Bieberle-Hütter, A. Harvey, A. Infortuna, U. Muecke, M. Prestat, J. Rupp and L. Gauckler, J. Power Sources, 2007, 173, 325-345. 
57 L. Dieterle, P. Bockstaller, D. Gerthsen, J. Hayd, E. IversTiffée and U. Guntow, Adv. Energy Mater., 2011, 1, 249-258.

58 A. J. Darbandi and H. Hahn, Solid State Ionics, 2009, 180, 1379-1387.

59 A. Evans, A. Bieberle-Hütter, H. Galinski, J. L. Rupp, T. Ryll, B. Scherrer, R. Tölke and L. J. Gauckler, Monatsh. Chem., 2009, 140, 975-983.

60 Y. Tao, J. Shao, W. G. Wang and J. Wang, Fuel Cells, 2009, 9, 679-683.

61 W. G. Wang and M. Mogensen, Solid State Ionics, 2005, 176, 457-462.

62 C. Peters, A. Weber and E. Ivers-Tiffée, J. Electrochem. Soc., 2008, 155, B730-B737.

63 J. Højberg and M. Søgaard, Electrochem. Solid-State Lett., 2011, 14, B77-B79.

64 F. Zhao, R. Peng and C. Xia, Mater. Res. Bull., 2008, 43, 370376.

65 M. Shah and S. A. Barnett, Solid State Ionics, 2008, 179, 2059-2064.

66 Y.-F. Sun, J.-H. Li, L. Cui, B. Hua, S.-H. Cui, J. Li and J.-L. Luo, Nanoscale, 2015, 7, 11173-11181.

67 D. Ding, X. Li, S. Y. Lai, K. Gerdes and M. Liu, Energy Environ. Sci., 2014, 7, 552-575.

68 Z. Jiang, C. Xia and F. Chen, Electrochim. Acta, 2010, 55, 3595-3605.

69 K. K. Hansen, M. Wandel, Y. L. Liu and M. Mogensen, Electrochim. Acta, 2010, 55, 4606-4609.

70 R. J. H. Voorhoeve, D. W. Johnson, J. P. Remeika and P. K. Gallagher, Science, 1977, 195, 827-833.

71 Y. Nishihata, J. Mizuki, T. Akao, H. Tanaka, M. Uenishi, M. Kimura, T. Okamoto and N. Hamada, Nature, 2002, 418, 164-167.

72 M. Uenishi, H. Tanaka, I. Tan, M. Taniguchi, N. Kajita, M. Kimura, K. Narita and H. Suzuki, AutoTechnology, 2007, 7, 44-47.

73 H. Tanaka, M. Taniguchi, M. Uenishi, N. Kajita, I. Tan, Y. Nishihata, J. i. Mizuki, K. Narita, M. Kimura and K. Kaneko, Angew. Chem., Int. Ed., 2006, 45, 5998-6002.

74 D. Neagu, G. Tsekouras, D. N. Miller, H. Menard and J. T. S. Irvine, Nat. Chem., 2013, 5, 916-923.

75 H. J. T. Ellingham, J. Soc. Chem. Ind., 1944, 63, 125-160.

76 D. Ding, M. Liu and M. Liu, ECS Trans., 2013, 57, 18011810.

77 R. Kiebach, C. Knöfel, F. Bozza, T. Klemensø and C. Chatzichristodoulou, J. Power Sources, 2013, 228, 170177.

78 X. Lou, Z. Liu, S. Wang, Y. Xiu, C. P. Wong and M. Liu, J. Power Sources, 2010, 195, 419-424.

79 T. Z. Sholklapper, C. Lu, C. P. Jacobson, S. J. Visco and L. C. De Jonghe, Electrochem. Solid-State Lett., 2006, 9, A376-A378.

80 S. Lee, N. Miller, H. Abernathy, K. Gerdes and A. Manivannan, J. Electrochem. Soc., 2011, 158, B735-B742.

81 J. D. Nicholas and S. A. Barnett, J. Electrochem. Soc., 2010, 157, B536-B541.

82 J. M. Serra and H.-P. Buchkremer, J. Power Sources, 2007, 172, 768-774.
83 A. J. Van Dillen, R. J. Terörde, D. J. Lensveld, J. W. Geus and K. P. De Jong, J. Catal., 2003, 216, 257-264.

84 P.-P. Jiang, S.-H. Zhang, Y.-L. Guo, Y. Guo, X.-Y. Wang and G.-Z. Lu, J. Inorg. Mater., 2004, 19, 634-640.

85 R. Küngas, J.-S. Kim, J. M. Vohs and R. J. Gorte, J. Am. Ceram. Soc., 2011, 94, 2220-2224.

86 H. Zhang and W. Yang, Chem. Commun., 2007, 4215-4217. 87 A. J. Samson, M. Søgaard, P. Hjalmarsson, J. Hjelm, N. Bonanos, S. P. V. Foghmoes and T. Ramos, Fuel Cells, 2013, 13, 511-519.

88 V. Dusastre and J. A. Kilner, Solid State Ionics, 1999, 126, 163-174.

89 E. Perry Murray, M. J. Sever and S. A. Barnett, Solid State Ionics, 2002, 148, 27-34.

90 A. Petric, P. Huang and F. Tietz, Solid State Ionics, 2000, 135, 719-725.

91 M. Sase, D. Ueno, K. Yashiro, A. Kaimai, T. Kawada and J. Mizusaki, J. Phys. Chem. Solids, 2005, 66, 343-348.

92 M. Backhaus-Ricoult, Solid State Ionics, 2006, 177, 21952200.

93 M. Backhaus-Ricoult, K. Adib, T. S. Clair, B. Luerssen, L. Gregoratti and A. Barinov, Solid State Ionics, 2008, 179, 891-895.

94 D. Chen, G. Yang, F. Ciucci, M. O. Tade and Z. Shao, J. Mater. Chem. A, 2014, 2, 1284-1293.

95 Y. Zhou, B. An, Y. Guo, R. Ran and Z. Shao, Electrochem. Commun., 2009, 11, 2216-2219.

96 T. Nagai, W. Ito and T. Sakon, Solid State Ionics, 2007, 177, 3433-3444.

97 W. Zhou, Z. Shao, R. Ran, W. Jin and N. Xu, Chem. Commun., 2008, 5791-5793, DOI: 10.1039/b813327a.

98 P. Hjalmarsson, J. Hallinder and M. Mogensen, J. Solid State Electrochem., 2012, 16, 2759-2766.

99 A. J. Samson, M. Søgaard and N. Bonanos, Electrochem. Solid-State Lett., 2012, 15, B54-B56.

100 L. Dieterle, P. Bockstaller, D. Gerthsen, J. Hayd, E. IversTiffée and U. Guntow, Adv. Energy Mater., 2011, 1, 249-258.

101 N. Imanishi, R. Ohno, K. Murata, A. Hirano, Y. Takeda, O. Yamamoto and K. Yamahara, Fuel Cells, 2009, 9, 215-221.

102 E. Mutoro, E. J. Crumlin, M. D. Biegalski, H. M. Christen and Y. Shao-Horn, Energy Environ. Sci., 2011, 4, 3689-3696.

103 M. Sase, K. Yashiro, K. Sato, J. Mizusaki, T. Kawada, N. Sakai, K. Yamaji, T. Horita and H. Yokokawa, Solid State Ionics, 2008, 178, 1843-1852.

104 M. J. Gadre, Y.-L. Lee and D. Morgan, Phys. Chem. Chem. Phys., 2012, 14, 2606-2616.

105 J. W. Han and B. Yildiz, Energy Environ. Sci., 2012, 5, 85988607.

106 E. J. Crumlin, E. Mutoro, S.-J. Ahn, G. J. la O', D. N. Leonard, A. Borisevich, M. D. Biegalski, H. M. Christen and Y. ShaoHorn, J. Phys. Chem. Lett., 2010, 1, 3149-3155.

107 J. Hayd, H. Yokokawa and E. Ivers-Tiffée, J. Electrochem. Soc., 2013, 160, F351-F359.

108 F. A. Kroger, Annu. Rev. Mater. Sci., 1977, 7, 449-475.

109 J. C. Ruiz-Morales, J. Canales-Vázquez, C. Savaniu, D. Marrero-López, W. Zhou and J. T. S. Irvine, Nature, 2006, 439, 568-571. 
110 D. Neagu, T.-S. Oh, D. N. Miller, H. Menard, S. M. Bukhari, S. R. Gamble, R. J. Gorte, J. M. Vohs and J. T. S. Irvine, Nat. Commun., 2015, 6(8120), 1-8.

111 G. Xiao, S. Wang, Y. Lin, Y. Zhang, K. An and F. Chen, ACS Appl. Mater. Interfaces, 2014, 6, 19990-19996.

112 Q. Qin, G. Wu, S. Chen, W. Doherty, K. Xie and Y. Wu, Electrochim. Acta, 2014, 127, 215-227.

113 D. Papargyriou and J. T. S. Irvine, Solid State Ionics, 2016, 288, 120-123.

114 H. Yoon, J. Zou, N. M. Sammes and J. Chung, Int. J. Hydrogen Energy, 2015, 40, 10985-10993.

115 R. Thalinger, M. Gocyla, M. Heggen, B. Klötzer and S. Penner, J. Phys. Chem. C, 2015, 119, 22050-22056.

116 L. Yang, Y. Choi, W. Qin, H. Chen, K. Blinn, M. Liu, P. Liu, J. Bai, T. A. Tyson and M. Liu, Nat. Commun., 2011, 2, 357.

117 W. Qi, K. Xie, M. Liu, G. Wu, Y. Wang, Y. Zhang and Y. Wu, RSC Adv., 2014, 4, 40494-40504.

118 H. Wei, K. Xie, J. Zhang, Y. Zhang, Y. Wang, Y. Qin, J. Cui, J. Yan and Y. Wu, Sci. Rep., 2014, 4, 5156.

119 J. Liu, P. Han, M. Dong, G. Fan, G. Qiao and J. Yang, Phys. B, 2012, 407, 891-895.
120 A. Refaat Ali, S. A. Mahmoud, Z. M. Farid and K. Atef, Phys. Status Solidi A, 1998, 165, 377-387.

121 A. Seko, N. Odagaki, S. R. Nishitani, I. Tanaka and H. Adachi, Mater. Trans., 2004, 45, 1978-1981.

122 T.-S. Oh, E. K. Rahani, D. Neagu, J. T. S. Irvine, V. B. Shenoy, R. J. Gorte and J. M. Vohs, J. Phys. Chem. Lett., 2015, 6, 51065110.

123 W. H. Kan, P. Dong, J.-S. Bae, S. Adams and V. Thangadurai, Solid State Ionics, 2016, 290, 90-97.

124 W. H. Kan, A. Huq and A. Manthiram, Chem. Mater., 2016, 28, 1832-1837.

125 W. H. Kan, A. Huq and A. Manthiram, Chem. Mater., 2015, 27, 7729-7733.

126 W. H. Kan, A. Huq and A. Manthiram, Chem. Commun., 2015, 51, 10447-10450.

127 M. Sale and M. Avdeev, J. Appl. Crystallogr., 2012, 45, 10541056.

128 Y.-F. Sun, X.-W. Zhou, Y. Zeng, B. S. Amirkhiz, M.-N. Wang, L.-Z. Zhang, B. Hua, J. Li, J.-H. Li and J.-L. Luo, J. Mater. Chem. A, 2015, 3, 22830-22838.

129 J. Zhang, K. Xie, Y. Gan, G. Wu, B. Ding, Y. Zhang and Y. Wu, New J. Chem., 2014, 38, 3434-3442. 